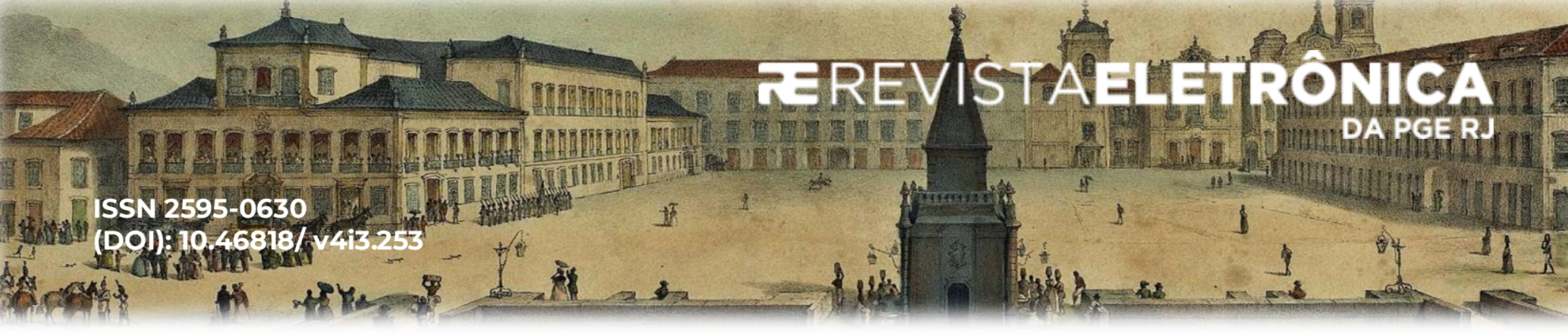

\title{
A LEGISLAÇÃO BASEADA EM EVIDÊNCIAS EMPÍRICAS E O CONTROLE JUDICIAL DOS FATOS DETERMINANTES DA DECISÃO LEGISLATIVA
}

\author{
EMPIRICAL EVIDENCE-BASED LEGISLATION AND THE JUDICIAL REVIEW \\ OF THE DETERMINING FACTS OF THE LEGISLATIVE DECISION
}

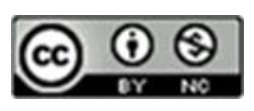

Roberta Simões Nascimento ${ }^{1}$

RESUMO: O artigo discute a utilização de evidências empíricas para a tomada de decisão legislativa, apresentando algumas dificuldades teóricas e práticas em torno da temática. Argumenta-se a falta de clareza conceitual sobre o que são evidências e sobre quais são os deveres em concreto a cargo dos legisladores na respectiva produção e consideração. Explicase que o movimento em prol da legislação baseada em evidências (evidence-based legislation) não se confunde com a pesquisa empírica no direito (empirical legal scholarship), e que a produção acadêmica advinda dessa última tendência não necessariamente produz (ou produzirá) legislação baseada em evidências, até mesmo porque nem sempre as pesquisas oferecem respostas claras e não necessariamente as evidências serão determinantes para a legislação. Apresenta-se a perspectiva potencialmente rival - embora também voltada para o aperfeiçoamento da elaboração legislativa - cujo foco está nas qualidades democráticas do processo legislativo. Analisa-se a sindicabilidade dos fatos determinantes via controle judicial (evidence-based judicial review), apontando as disfuncionalidades da prática brasileira nessa matéria. Por fim, apontam-se alguns desafios e recomendações quanto à consideração e à revisão judicial das evidências consideradas (ou não) pelos legisladores.

PALAVRAS-CHAVE: Evidence-based legislation; Premissa fática; Decisão legislativa; Fatos legislativos; Controle judicial.

ABSTRACT: The article discusses the use of empirical evidence for legislative decision making, presenting some theoretical and practical difficulties around it. It argues that there is a lack of conceptual clarity about what is evidence and what are the concrete duties of legislators in producing and considering it. It is explained that the movement towards evidence-based legislation is not the same as empirical legal scholarship, and that the academic production resulting from the latter trend does not necessarily produces (or will produce) evidence-based legislation, even because empirical studies do not always provide clear answers or evidence will not always be determinant for legislation. A potentially conflicting perspective is presented - although also aimed at improving law-making - focusing on the democratic qualities of the

\footnotetext{
${ }^{1}$ Professora adjunta na Universidade de Brasília (UnB). Doutora em Direito pela Universidade de Alicante, Espanha. Doutora e mestre em Direito pela UnB. Advogada do Senado Federal desde 2009.
} 
legislative process. The syndicability of determining facts via judicial control (evidence-based judicial review) is analyzed, pointing out the dysfunctionalities of the Brazilian practice on this matter. Finally, the article presents some challenges and recommendations regarding the consideration and judicial review of the evidence considered (or not) by legislators.

KEYWORDS: Evidence-based legislation; Factual premise; Legislative decision; Legislative facts; Judicial review.

SUMÁRIO: Introdução. 1. As evidências, a racionalização da decisão legislativa e as contradições teóricas. 2. O controle judicial dos fatos legislativos e alguns de seus problemas. 3. Problemas e desafios emergentes da consideração de evidências na arena legislativa e da revisão judicial das evidências usadas (ou não) pelos legisladores. 4. Conclusões. Referências.

SUMMARY: Introduction. 1. Evidences, rationalization of legislative decision and theoretical contradictions. 2. Judicial control of legislative facts and some of its problems. 3. Issues and emergent challenges from considering evidences in legislative arena and from judicial review of used, or not used, evidences for legislator. 4. Conclusions. References.

\section{Introdução $\mathbf{0}^{2}$}

O processo decisório que culmina na aprovação de leis (e, em grande medida, das normas em geral) envolve, em um primeiro momento, a valoração de fatos, isto é, de uma dada realidade, a qual pode ser considerada negativa ou positiva e, conforme o caso, digna de incentivos voltados para evitá-la ou promovê-la. Embora o "tratamento legislativo dos fatos" seja um assunto negligenciado nos estudos sobre a elaboração legislativa, essa "premissa fática" da decisão legislativa é um ingrediente necessário e importante no processo legislativo. A reivindicação de que essa premissa precisa contar com uma base empírica de boa qualidade, que oriente, inclusive, a providência a ser tomada, é questão que vem recebendo cada vez mais atenções e merece aprofundamento e maior clareza conceitual.

Na etapa pré-legislativa (isto é, antes mesmo da tramitação de uma proposta dentro dos parlamentos), o que costuma desencadear uma decisão legislativa (ou normativa em geral, doravante deve-se reputar implícita essa menção quando pertinente) costuma ser o surgimento de uma discussão sobre uma disfunção social ou um problema (que pode ser real ou aparente), cuja solução exigiria a intervenção legislativa à luz dos valores, baseados em crenças,

\footnotetext{
${ }^{2}$ Uma versão anterior deste trabalho foi apresentada no VI Seminário de Integração FGV Direito Rio e Faculdade de Direito da UERJ - Transformações do Direito Administrativo: Debates e Estudos Empíricos em Direito Administrativo e Regulatório, no dia 24 de novembro de 2021. Agradeço aos participantes do seminário pelo produtivo debate e, de forma especial, aos Professores Leandro Molhano Ribeiro e Patrícia Baptista, pelos comentários à versão anterior deste trabalho.
} 
ideologias ou interesses da sociedade, diante de um contexto em concreto. Dito com outras palavras, o descompasso entre uma determinada situação no plano dos fatos - uma questão social ou econômica, por exemplo - e a resposta jurídica dada pelo ordenamento vigente é o que justificaria a necessidade de inserção de uma nova previsão legal.

De acordo com essa perspectiva descritivo-analítica, a elaboração legislativa pressupõe, ainda que de modo abstrato, a apreciação sobre os estados de coisas do mundo de forma prévia ao estabelecimento de normas, fixando condutas como proibidas, obrigatórias ou facultativas. Disso emerge a importância de que sejam aportadas informações que sirvam de base para essa discussão. Inclusive, o ponto de partida do movimento que se vem chamando "políticas públicas baseadas em evidências"3 (evidence-based policy ou EBP) é, precisamente, a exigência de dados empíricos de boa qualidade (ou seja, coletados de acordo com o método científico) como caminho para conferir credibilidade à apreciação feita em torno da realidade e do que deve ser feito. Só assim seria possível reputar acertada a opção da decisão legislativa.

Nada obstante a razoabilidade dessa abordagem prescritiva da legislação baseada em evidências, voltada para conferir maior racionalidade à decisão legislativa, não existe muita clareza sobre o que significaria "usar evidências" na elaboração legislativa, se é necessário em todos os casos, nem sobre quais seriam, efetivamente, as condutas a serem levadas a cabo pelos legisladores nesse momento. Ao mesmo tempo em que não se define o grau de exigência ou rigor na obtenção dessas informações da dimensão fática, tampouco estão explicados como se daria seu controle e quais seriam as consequências da eventual não observância dessa metapolítica legislativa.

Em resumo, pendem de resposta algumas indagações como: é necessária a realização de pesquisas empíricas previamente a uma intervenção legislativa em todos os casos? E para o controle judicial das premissas fáticas da legislação (os chamados "fatos legislativos”) também é necessária a realização desses procedimentos? Que tipo de vício representa a falta de veracidade dos fatos determinantes da produção legislativa? Como diferenciar a existência da própria realidade em si e da valoração política dessa realidade (que sim pode ser, em certa medida, objeto de discricionariedade legislativa)?

\footnotetext{
${ }^{3} \mathrm{O}$ termo evidence (do inglês) vem sendo traduzido para o português indistintamente como "evidência". A rigor, na língua original, a palavra tem diferentes acepções, sobretudo em seu uso técnico-jurídico, podendo significar, conforme o contexto, diversos meios de prova, como sinônimo de indício, amostra, sinal, pista, comprovante, demonstrativo, atestado, testemunho, depoimento, além de outras variações à luz dos institutos peculiares ao respectivo sistema jurídico. Essa variação lexical exigiria um maior preciosismo na tradução da expressão evidence-based para o português, que deveria ser "baseado em provas". No entanto, considerando que já se disseminou a tradução de evidence como evidência, justifica-se a opção adotada no presente texto.
} 
O presente trabalho tem por objeto apresentar algumas considerações sobre a temática que se acaba de expor, adotando a seguinte estrutura: na próxima seção, faz-se uma breve exposição sobre os avanços teóricos voltados para aperfeiçoar o momento da produção legislativa, apresentando duas tendências com focos de preocupação diferentes, com pano de fundo para mostrar algumas das dificuldades envolvendo a utilização de "evidências" na elaboração das leis. Depois, dedica-se uma seção ao controle judicial dos fatos determinantes da legislação. Na sequência, são levantados alguns problemas e desafios emergentes da consideração de evidências na arena legislativa e da revisão judicial das evidências usadas (ou não) pelos legisladores.

\section{As evidências, a racionalização da decisão legislativa e as contradições teóricas.}

Como se acaba de indicar na introdução, o esquema analítico que culmina em uma intervenção legislativa tem, como uma de suas fases, a definição de um "problema", isto é, uma situação de fato que, segundo a avaliação dos atores (que podem ser um segmento da sociedade, partidos políticos, grupos de pressão, algum ente institucional, etc.), é percebida como uma tensão entre a realidade que se vive e a realidade desejada. ${ }^{4}$

$\mathrm{Na}$ verdade, diante de uma mesma situação, costuma existir uma multiplicidade de demandas - inclusive, com anseios diametralmente opostos -, o que dificulta a tarefa dos legisladores em apreciar as reivindicações de modo objetivo. A capacidade institucional do Poder Legislativo para proceder a essa verificação é limitada. ${ }^{5} \mathrm{Na}$ maioria das vezes, simplesmente são "encampadas" as análises feitas pelos atores sociais e, na falta de outra expressão melhor, pode-se dizer que os legisladores muitas vezes simplesmente "aceitam" os problemas tal como definidos por esses atores. ${ }^{6}$

\footnotetext{
${ }^{4}$ Há farta bibliografia sobre a matéria. Além da literatura produzida na análise das políticas públicas, há os focos da legística, da legisprudence e da metódica. Por todos, confiram-se os seguintes: BARDACH, Eugene. A Practical Guide for Policy Analysis. The Eightfold Path to More Effective Problem Solving. 4. ed. Thousand Oaks: CQ Press, 2012, p. 1-11; DELLEY, Jean-Daniel. Pensar a lei. Introdução ao pensamento metódico. Cadernos da Escola do Legislativo, v. 7, n. 12, p. 101-143, jan./jun. 2004, p. 102.

${ }^{5}$ SUNSTEIN, Cass R.; VERMEULE, Adrian. Interpretation and Institutions. Michigan Law Review, v. 101, n. 4, p. 885-951, 2003.

${ }^{6}$ Nesse sentido, por exemplo: BERGER, Peter L; LUCKMANN, Thomas. A construção social da realidade: tratado de sociologia do conhecimento. 36 ed. Petrópolis: Vozes, 2014; LINDBLOM, Charles E. O processo de decisão política. Brasília: Editora Universidade de Brasília, 1981; SIMON, Herbert A. El comportamiento administrativo. Estudio de los procesos decisorios en la organización administrativa. Madrid: Aguilar, 1970.
} 
Além disso, diferentemente do que ocorre no processo judicial, não existem restrições procedimentais - por exemplo, normas fixando como se deve dar a colheita das "provas" - a que os legisladores tenham que se submeter com relação ao uso ou não uso de fatos como base para a elaboração legislativa. Desde um ponto de vista estritamente jurídico positivista, a legislação seria um fenômeno autoritativo e, mesmo à luz das disposições da Constituição, nada impediria que se legisle "sem fatos" e, a rigor, sem justificações, desde que a legislação editada seja suficientemente razoável e atenda aos requisitos formais do processo legislativo. Ou seja, à luz dessa visão tradicional, não existiria um parâmetro normativo claro (isto é, extraível do texto constitucional) que permitisse um controle bem desenvolvido sobre os materiais fáticos usados como base para a aprovação de uma lei. Como será visto no próximo item, a prática parece não ser bem assim: cada vez mais ofact-finding legislativo tem importância na jurisdição constitucional.

Seja como for, importa chamar a atenção para o fato de que também o raciocínio legislativo conta com uma premissa fática, consistente nos "fatos legislativos", os quais podem ser definidos como uma ampla categoria de fatos usados para informar a decisão legislativa (e também das agências), ${ }^{7}$ considerando as circunstâncias e o background, à semelhança da chamada occasio legis. Nesse sentido, os fatos legislativos são de caráter geral e se contrapõem aos fatos adjudicativos, controvertidos entre as partes dentro de um processo judicial. ${ }^{8}$ Dentro dos fatos legislativos também estão inseridos os juízos ou previsões sobre os efeitos que a inserção de uma disposição normativa terá no mundo dos fatos. ${ }^{9}$ No entanto, tais fatos legislativos não necessariamente são "evidências" na linha do movimento da legislação evidence-based..$^{10}$ Ambos, fatos e evidências, têm em comum a relação com o mundo como é, mas não há equivalência entre um e outro (nem todos os fatos considerados são evidências).

\footnotetext{
${ }^{7}$ De forma original, Kenneth Culp Davis definiu os fatos legislativos como os que “(...) are utilized for informing a court's legislative judgement on questions of law and policy" (DAVIS, Kenneth Culp. An approach to problems of evidence in the administrative process. Harvard Law Review, v. 55, n. 3, p. 364-425, 1942, p. 404).

${ }^{8}$ DAVIS, Kenneth Culp. An approach..., cit.; WOOLHANDLER, Ann. Rethinking the Judicial Reception of Legislative Facts. Vanderbilt Law Review, v. 41, n. 1, p. 111-126, 1988, p. 112-4.

${ }^{9}$ Por exemplo, que os incentivos fiscais a serem concedidos com vistas a reduzir as desigualdades regionais efetivamente se prestam a esse propósito, isto é, terão esse feito concreto na realidade. Ou, a título ilustrativo, no exemplo dado por Ann Woolhandler, que a pena de morte não detém a criminalidade (WOOLHANDLER, Ann. Rethinking the..., cit., p. 114).

${ }^{10}$ Mesmo sem pretensões de aprofundar na história desse movimento, convém registrar que o marco de referência do evidence-based policy ou EBP foi o da medicina baseada em evidências, no início dos anos noventa. A reivindicação teve início precisamente junto às políticas sanitárias e, depois, de modo mais amplo sob a seguinte reivindicação: se é esperado que os médicos baseiem suas decisões nos achados da investigação científica, os políticos também deveriam fazer o mesmo. Grosso modo, foi a origem do movimento em prol das políticas públicas baseadas em evidências. Para mais detalhes: HAM, Chris; HUNTER, David; ROBINSON, Ray. Evidence based policy making. Research must inform health policy as well as medical care. $B M J$, v. 310, p. 71-72, 14 jan. 1995; MACINTYRE, Sally; PETTICREW, Mark. Good intentions and received wisdom are not enough. Journal of Epidemiology \& Community Health, v. 54, n. 11, p. 802-803.
} 
Existem algumas das dificuldades de manejar a categoria "evidências" na elaboração da legislação. Nem todos estão de acordo sobre o que são evidências ou o quanto de pesquisa (isto é, o esforço a ser dedicado) é necessário para encontrar evidências que embasem a decisão legislativa. Como aponta Richard French, ${ }^{11}$ há grande divergência em torno do conceito. $\mathrm{O}$ próprio autor define evidência como o "produto da pesquisa", ${ }^{12}$ isto é, o conhecimento produzido de acordo com os padrões das disciplinas acadêmicas relevantes. ${ }^{13,14}$

Por seu turno, Marcelo Marchesini da Costa e outros ${ }^{15}$ também vão por caminho semelhante, entendendo que evidências seriam somente as "obtidas por meio de métodos científicos aceitos pela comunidade de referência". Por isso, tais autores excluem da qualificação como evidências o seguinte: 1) a opinião de especialistas; 2) casos anedóticos (isto é, relatos informais, incompletos ou pouco rigorosos); e 3) estudos em andamento, preliminares, que contam com resultados meramente parciais ou inconclusos. Carlos Orsi ${ }^{16}$ também exclui o relato pessoal como evidência científica.

Além disso, o juízo sobre a necessidade de base em evidências para a tomada de decisão legislativa também recebe tratamento diferenciado conforme as diferentes perspectivas teóricas. Richard French ${ }^{17}$ enumerou quatro escolas de pensamento sobre o tema: 1) de reforço; 2) de reforma; 3) de reinvenção; e 4) de rejeição. A primeira escola (de reforço) representa o tipo ideal do movimento EBP: de modo geral, se a política pública não é feita com base em

\footnotetext{
${ }^{11}$ FRENCH, Richard D. Evidence-Based Policy: Four Schools of Thought. Canadian Public Administration, n. 61 , i. 3 , p. $1-29$, s/d.

${ }^{12}$ FRENCH, Richard D. Evidence-Based..., cit., p. 2.

${ }^{13}$ Já Maurício Mota Saboya Pinheiro traz uma definição mais ampla de evidências, como os "conhecimentos produzidos a partir de métodos sistematizados e reprodutíveis", abrangendo, em lista não exaustiva: "i) identificação precisa de um problema de pesquisa, com variáveis dependentes e independentes bem delimitadas; ii) revisão da literatura acadêmica sobre o assunto; iii) coleta sistemática de dados e informações; iv) tratamento dos dados e informações com métodos quantitativos ou qualitativos rigorosos; v) discussão detalhada dos resultados; vi) publicação dos resultados em periódicos científicos; e vii) publicação em periódicos de universidades ou institutos de pesquisa." (PINHEIRO, Maurício Mota Saboya. Políticas públicas baseadas em evidências: uma avaliação crítica. In: BOLETIM de Análise Político-Institucional. Usos de evidências em políticas públicas federais, n. 24. Brasília: Instituto de Pesquisa Econômica Aplicada (IPEA), 2020, p. 17-27, p. 17).

${ }^{14}$ Para além da própria definição sobre o que são evidências, no campo das EBP também é controvertido o debate sobre a possibilidade de uma hierarquização de evidências, a partir de sua qualidade, mensurável conforme o rigor metodológico do desenho do projeto, coleta de dados e respectiva análise. Para uma visão, confira-se: FERREIRA, Helder. Análise de qualidade de evidências científicas utilizadas em política pública: aplicação a documentos relativos à tramitação do PL $n^{\circ} 3.722 / 2012$, que flexibiliza o controle de armas de fogo. In: BOLETIM de Análise Político-Institucional. Usos de evidências em políticas públicas federais, n. 24. Brasília: Instituto de Pesquisa Econômica Aplicada (IPEA), 2020, p. 125-134.

${ }^{15}$ COSTA, Marcelo Marchesini da et al. O que são evidências para políticas públicas? Folha de São Paulo, 21 ago. 2021. Disponível em: https://www1.folha.uol.com.br/opiniao/2021/08/o-que-sao-evidencias-para-politicaspublicas.shtml. Acesso em: 19 set. 2021.

${ }^{16}$ ORSI, Carlos. Por que relato pessoal não conta como evidência científica? Questão de Ciência, 13 abr. 2021. Disponível em: https://www.revistaquestaodeciencia.com.br/questionador-questionado/2021/04/13/por-querelato-pessoal-nao-conta-como-evidencia. Acesso em: 19 set.

${ }^{17}$ FRENCH, Richard D. Evidence-Based..., cit.
} 
evidências, então sua motivação foi fruto de interesse próprio, poder, ideologia, ignorância, puro "eleitoralismo", cooptação pelas "elites", submissão a "interesses", etc. Essa primeira corrente do movimento EBP reflete, como se vê, uma visão idealizada e ingênua sobre o papel das evidências e do processo decisório.

A segunda escola (de reforma) reconhece as falhas da EBP na vertente anterior (que acaba depositando na conta dos formuladores o reconhecimento dos méritos das evidências), considerando o modelo tradicional de transmissão da ciência e coloca mais prioridade no reconhecimento de que as evidências são mais úteis para esclarecer e educar os formuladores de políticas públicas, em vez de oferecer soluções para problemas políticos específicos. A escola da reforma aceita que há vários tipos de evidências e, entre essas, a que mais tem chances de influenciar a formulação de políticas públicas é a fornecida por pesquisadores em contato direto com os formuladores de políticas públicas.

A terceira escola (de reinvenção), vislumbrando existir um problema de governança epistêmica no movimento da EBP, propõe uma reinvenção nas relações entre as pesquisas científicas e a política, o que exigiria uma autorregulação do processo de elaboração das políticas públicas pelos governos interessados em aproveitar as provas, de modo a oportunizar uma avaliação do conhecimento, envolvendo a triagem de estudos (pesquisas) e o controle de qualidade. A escola da reinvenção prescreve um compromisso para a elaboração de políticas públicas.

A quarta escola (de rejeição), sem negar o valor das evidências para a elaboração de políticas, rejeita as pretensões da EBP de oferecer uma melhoria fundamental nessa atividade, na medida em que depositar na ciência a fonte de salvação contra a ideologia é em si também uma ideologia. Para a escola da rejeição, a tentativa de criar um ambiente seguro e previsível é inapropriado, pois a ciência também é autorreferencial, criativa e ambígua, ou seja, seus métodos não são infalíveis. Descartam-se o mito da racionalidade e a reforma do processo político. Essencialmente, a escola da rejeição atribui autoridade mais limitada às evidências e propõe uma postura de humildade por parte dos especialistas.

Mesmo com esse esforço de Richard French em organizar as diversas linhas de pensamento em quatro escolas, percebe-se uma grande variedade de opiniões tanto sobre a viabilidade da EBP, quanto no que diz respeito às práticas ou ao que deve ser feito para alcançar a legislação baseada em evidências. ${ }^{18}$ Mesmo assim, na linha do que afirmam Patricia Popelier

${ }^{18}$ FRENCH, Richard D. Evidence-Based..., cit., p. 19. 
e Victoria Verlinden, ${ }^{19}$ é possível constatar que a EBP, juntamente com a avaliação de impacto, são as duas grandes ferramentas voltadas para constranger o processo decisório legislativo e para forçar uma preparação mais cuidadosa das alternativas legislativas. Nos modelos que lançam as bases para uma legislação racional, fica evidenciado que os legisladores precisariam de mecanismos que deem suporte às suas decisões.

Sem prejuízo dessas perspectivas voltadas para a racionalização do processo legislativo, não deve passar desapercebida a existência de outra tendência de relevo, aparentemente conflitante, mas na verdade perfeitamente conciliável, consistente na necessidade de que promover a participação dos grupos de interesse e do público em larga escala, com vistas a democratizar o processo deliberativo. É dizer, as evidências não são determinantes em todos os casos. E mais: como argumentam Jeffrey J. Rachlinski e Cynthia R. Farina, ${ }^{20}$ oportunizar esse tipo de participação é um dos melhores mecanismos para reduzir o eventual excesso de confiança dos especialistas. Trata-se de promover o "desenviesamento" das decisões e, ao mesmo tempo, de evitar as falhas regulatórias a partir de "constrangimentos democráticos". Como explicam os autores, uma estratégia regulatória first-best pode acabar sendo rejeitada em razão de uma forte resistência da opinião pública. ${ }^{21}$

Essa peculiaridade inerente à elaboração das leis nos parlamentos - consistente na necessidade de que o processo legislativo concilie a base em alguma evidência com os requerimentos democráticos - pode ter determinado a previsão do Decreto $n^{\circ} 10.411 / 2021$, art. $1^{\circ}, \S 3^{\circ}$, pela qual a análise de impacto regulatório não se aplica às propostas de edição de decreto ou aos atos normativos a serem submetidos ao Congresso Nacional. Embora não imune a críticas, a escolha pode ter sido fruto do reconhecimento no sentido de que o parlamento não fica atado às análises de custo-benefício ou eventuais outras considerações de ordem técnica, pois as legislaturas também cumprem outras funções representativas. Essa característica da legislação (que nesse ponto se diferencia, de modo especial, em comparação com a regulação) ${ }^{22}$

19 POPELIER, Patricia; VERLINDEN, Victoria. The Context of the Rise of Ex Ante Evaluation. In: VERSCHUUREN, Jonathan (Ed.). The Impact of Legislation: A Critical Analysis of Ex Ante Evaluation. Boston: Martinus Nijhoff Publishers, 2009, p. 13-37.

${ }^{20}$ RACHLINSKI, Jeffrey J.; FARINA, Cynthia R. Cognitive Psychology and Optimal Government Design. Cornell Law Review, v. 87, n. 2, p. 549-615, 2002, p. 588-9.

${ }^{21}$ RACHLINSKI, Jeffrey J.; FARINA, Cynthia R. Cognitive Psychology..., cit., p. 591-2.

${ }^{22}$ Outras diferenças e semelhanças entre a legislação e regulação podem ser vistas em: KOSTI, Nir; LEVI-FAUR, David; MOR, Guy. Legislation and regulation: three analytical distinctions. The Theory and Practice of Legislation, v. 7, n. 3, p. 169-178, 2019. Embora não haja um consenso teórico, os autores apresentam três perspectivas: a primeira diferencia a legislação (feita pelos parlamentos) da regulação (aprovada pelas agências) como duas esferas bastante separadas (enquanto a legislação traça os princípios das políticas públicas, a regulação implementa esses princípios, concretizando a legislação); a segunda perspectiva coloca a legislação como uma parte da regulação, ou seja, a regulação pode ser feita de diferentes maneiras, sendo uma delas a aprovação de leis; e a terceira perspectiva representaria precisamente o contrário da segunda, isto é, a regulação como uma 
- acredita-se - é um dos grandes mal-entendidos sobre a reinvindicação de legislação baseada em evidências.

Sem pretensões de aprofundar aqui na crítica teórica quanto à escassez de estudos voltados para explorar, especificamente, o papel do parlamento dentro das preocupações regulatórias (especialmente no Brasil, vê-se crescente atenção para com a teoria da regulação, mas poucos avanços com a teoria da legislação), por ora o que parece relevante é mostrar que o movimento da legislação baseada em evidências (evidece-based legislation) não é o mesmo e não se confunde com a pesquisa empírica no direito (empirical legal scholarship), e que a produção acadêmica advinda dessa última tendência não necessariamente produz (ou produzirá) legislação baseada em evidências. ${ }^{23}$ Como explica Jeffrey J. Rachlinski, ${ }^{24}$ ainda não é possível saber se um produzirá ou de fato ajudará o outro.

Jeffrey J. Rachlinski dá o exemplo da pena de morte nos Estados Unidos. As pesquisas empíricas produzidas não foram capazes de chegar a um consenso sobre se a pena de morte é ou não um instrumento hábil para deter a criminalidade. Com base nos mesmos dados, os pesquisadores chegam a conclusões diametralmente opostas (alguns sugerem que a pena capital não teria efeitos sobre crimes violentos, ao passo que outros afiram que cada execução impediu outros dezoito homicídios). Na prática, portanto, não haveria evidências nem para um lado, nem para o outro. Para Jeffrey J. Rachlinski, isso demonstra que há claros problemas em converter a pesquisa empírica (empirical legal scholarship) em legislação baseada em evidências. ${ }^{25}$ Além disso, estudos empíricos também podem ser inconclusivos ou oferecer um elemento fraco para a tomada de decisões em matéria de políticas públicas.

$\mathrm{Na}$ prática, as evidências competem com outros elementos, potencialmente mais persuasivos, que também informam a adoção das leis ou políticas públicas. Quanto a esse ponto, Giandomenico Majone ${ }^{26}$ chama a atenção para o fato de que "argumentos fáticos" nem sempre são o bastante com vistas à adoção de determinadas políticas públicas e, por vezes, a persuasão

\footnotetext{
subcategoria da legislação, de modo que, desde uma teoria geral, a legislação tem muitas funções, sendo uma delas a regulação. Para os fins do presente trabalho, acredita-se que a legislação e a regulação até têm pontos de convergência (para usar a linguagem dos diagramas de Venn, equivaleriam a dois conjuntos com uma intersecção em comum, não na forma de conjuntos completamente separados ou um contido no outro, como usados na referência indicada). Seja como for, é importante destacar os outros papeis exercidos especificamente pela legislação, mas não pela regulação.

${ }^{23}$ Ajudar os formuladores de políticas públicas seria uma das razões para realizar pesquisas empíricas no direito. Nesse sentido, por exemplo: EISENBERG, Theodore. Why Do Empirical Legal Scholarship? San Diego Law Review, v. 41, n. 4, p. 1741-1746, 2004.

${ }^{24}$ RACHLINSKI, Jeffrey J. Evidence-based law. Cornell Law Review, v. 96, i. 4, p. 901-924, 2011, p. 910.

${ }^{25}$ RACHLINSKI, Jeffrey J. Evidence-based..., cit., p. 912.

${ }^{26}$ MAJONE, Giandomenico. Evidence, Argument, and Persuasion in the Policy Process. New Haven: Yale University Press, 1989, p. 39.
} 
depende de outras estratégias. A persuasão - no sentido da utilização de outros argumentos com efeito "racionalizador", diferentes dos que conduziram à adoção de certa posição -, explica Giandomenico Majone, é um passo preliminar necessário para ganhar a atenção do público e da própria classe política com vistas à consideração de diferentes enfoques para o problema que se discute. ${ }^{27}$

Adicionalmente a essa dimensão política do processo decisório, deve-se adicionar o problema do inevitável uso "estratégico" das evidências na arena legislativa, é dizer, o uso de modo seletivo, com o objetivo de "enviesar" decisões. Como aponta Acir Almeida:28 1) a lógica da representação democrática em sociedades plurais, 2) o fato de os parlamentos serem formados por atores com interesses conflitantes, 3) o pouco ou nenhum conhecimento especializado dos parlamentares, e 4) a incerteza e a assimetria informacional inerentes à dinâmica parlamentar, tornam os parlamentos um terreno especialmente fértil à manipulação da informação. Fica claro, portanto, que o conhecimento científico não é capaz de eliminar ou aplacar as diferenças irreconciliáveis de interesses e valores na arena legislativa (e não há nada de errado ou ilegítimo nisso).

Reconhecendo que é essa a realidade, Acir Almeida tenta identificar quais seriam as condições políticas e os incentivos para a aquisição e compartilhamento de evidências no cenário das comissões permanentes da Câmara dos Deputados. Sua conclusão não é tão pessimista quanto o diagnóstico poderia sugerir: dependendo de como se organiza o processo decisório, a divergência de interesses e a heterogeneidade das preferências favoreceriam à produção de informação de mais qualidade (ou seja, o uso de evidências na fase legislativa), ainda que isso não elimine a "politização" e a "manipulação" das evidências, como indicado.

A ideia de que as evidências são utilizadas de modo seletivo ou de diferentes maneiras na construção de leis e políticas públicas também está presente no trabalho de Nabil Amara, Mathieu Ouimet e Réjean Landry, ${ }^{29}$ que separaram a mobilização, captação, interpretação e

\footnotetext{
${ }^{27}$ Nas palavras do próprio autor: “(...) policymakers tend to think in traditional categories, or in terms of alternatives that are unduly restricted in relation to their own objectives. Persuasion is needed to induce them to consider different formulations or approaches to the issue under discussion since the psychological effect of factual arguments may not be strong enough to overcome the inertia of long-established patterns of thought. Experience also shows that facts and statistics are seldom sufficient to bring about changes in behavior - even after the need for a change has become clear. For this reason, public policies to induce citizens to adopt healthier lifestyles tend to rely at least as much on persuasion as on objective information." (MAJONE, Giandomenico. Evidence, Argument ..., cit., p. 39).

${ }^{28}$ ALMEIDA, Acir. Heterogeneidade de preferências e o uso de evidências na Câmara dos Ceputados. In: BOLETIM de Análise Político-Institucional. Usos de evidências em políticas públicas federais, n. 24. Brasília: Instituto de Pesquisa Econômica Aplicada (IPEA), 2020, p. 115-124.

${ }^{29}$ AMARA, Nabil; OUIMET, Mathieu; LANDRY, Réjean. New evidence on instrumental, conceptual, and symbolic utilization of university research in government agencies. Science Communication, v. 26, n. 1, p. 75-106, 2004.
} 
utilização de evidências (mais especificamente, de pesquisas universitárias) em três perspectivas de uso: instrumental, conceitual e simbólico. No uso instrumental, as evidências são utilizadas para resolver os problemas (na linha da escola de reforço a que se referia Richard French, com caráter determinante, o que é severamente criticado pela falta de realismo). No uso conceitual, as evidências são usadas de modo difuso, mais como elemento de apoio (de forma parecida ao retrato apontado por Giandomenico Majone). Por seu turno, o uso simbólico das evidências se refere a tais insumos como "munição política", no âmbito do processo de barganha decisória. Esse papel simbólico representa, precisamente, o mau uso das evidências (como alerta Acir Almeida). A pesquisa de Nabil Amara, Mathieu Ouimet e Réjean Landry, a partir de elementos empíricos, sugere que os três tipos de usos indicados desempenham simultaneamente um papel significativo nas agências governamentais. Em todo caso, o que se pretende é indicar os possíveis usos táticos das evidências no mundo real.

Além dessa chamada de atenção dos autores citados acima quanto aos diferentes usos das evidências nos processos reais de construção de leis e políticas públicas, também convém retomar as considerações sobre a dimensão democrática da legislação a partir da perspectiva capitaneada principalmente por Jeremy Waldron, ${ }^{30}$ cujas preocupações atribuem grande peso aos distintos interesses em conflito e às características do processo deliberativo, sobretudo nas situações em que existem desacordos profundos. Nessa vertente, o olhar para a legitimidade da decisão poderia ir de encontro aos outros valores mais racionalizantes ou, no mínimo, tirar algum peso das evidências empíricas eventualmente colocadas como suporte para a tomada de uma decisão legislativa.

Jeremy Waldron considera que os aspectos institucionais dos parlamentos conferem à legislação um modelo mais "atrativo", em comparação à atividade normativa dos juízes, por decretos ou das agências reguladoras. $\mathrm{O}$ autor se importa menos com o conteúdo material das decisões legislativas e mais com as características dos parlamentos como: 1) a composição por legisladores eleitos e responsáveis (accountable), 2) a dedicação de modo transparente à elaboração legislativa (isto é, transparência quanto à função institucional, não necessariamente sobre como ela é desenvolvida na prática), 3) o tamanho (os parlamentos são corpos numerosos) a proporcionar diversidade de pontos de vista, opiniões e experiência, ${ }^{31} 4$ ) a representatividade

\footnotetext{
${ }^{30}$ WALDRON, Jeremy. Political political theory: essays on institutions. Cambridge: Harvard University Press, 2016; __ Principles of legislation. In: BAUMAN, Richard W.; KAHANA, Tsvi (Eds.). The Least Examined Brach: the Role of Legislatures in the Constitutional State. Cambridge: Cambridge University Press, 2006, p. 1532; _. Derecho y desacuerdos. Madrid: Marcial Pons, 2005; Martins Fontes, 2003.

31 Nas palavras do próprio Jeremy Waldron: "The key here is diversity. Different people bring different perspectives to bear on the issues under discussion, and the more people there are, the greater the richness and
} 
das legislaturas, que favorece à despersonalização de demandas e opiniões e cria uma distância, um filtro, uma mediação, no processo político. Na perspectiva de Jeremy Waldron, tais elementos confeririam as credenciais democráticas da legislação, que é o seu foco de atenções.

Em resumo, Jeremy Waldron defende os seguintes sete princípios procedimentais da legislação: 1) o princípio da legislação explícita, ou seja, quando se faz ou se modifica uma lei, deve-se fazê-lo expressamente; 2) o dever de cuidado ao legislar, tendo em vista tanto a importância da lei quanto dos interesses e liberdades que estão em jogo; 3) o princípio da representação, que requer que o direito seja criado em foro que dá voz e reúne informação sobre todas as opiniões e interesses importantes na sociedade; 4) o princípio do respeito pelo desacordo, e requisitos concomitantes como o princípio da oposição real; 5) o princípio da deliberação e o dever de "responsividade" ou sensibilidade à deliberação; 6) o princípio da formalidade legislativa, que inclui o debate estruturado e com foco nos textos das propostas legislativas que se discutem; e 7) o princípio da igualdade política e o procedimento de decisão que tem lugar dentro de parlamentos eleitos, por exemplo, a regra de decisão majoritária. ${ }^{32}$

Por seu turno, Luc J. Wintgens ${ }^{33}$ também constrói sua teoria da legislação calcada em quatro princípios cujo fundamento último é a liberdade (autonomia individual do homem). São eles: 1) alternatividade; 2) densidade normativa; 3) coerência e 4) temporalidade. Para Luc J. Wintgens, as limitações à liberdade devem ser justificadas e, por isso, os legisladores têm deveres, concretizados a partir dos referidos princípios. Luc J. Wintgens até reconhece que, se a legislação pretende alguma racionalidade, precisa se referir aos fatos com os quais pretende estar conectada. No entanto, o autor é claro em "temperar" tal consideração, explicando que o conhecimento dos fatos depende de um contexto de participação ou prática social dentro do qual obtém significado. ${ }^{34} \mathrm{Em}$ outras palavras, embora haja um dever de averiguação fática adequada a cargo dos legisladores, essa obrigação deve estar inserida dentro da interação social.

\footnotetext{
diversity of viewpoints is going to be. When diverse perspectives are brought together deliberatively in a collective decision-making process, that process will be informed by much greater informational resources than attend the decision-making of any single individual" (WALDRON, Jeremy. Political political..., cit., p. 132).

${ }^{32}$ WALDRON, Jeremy. Principles ..., cit., p. 18.

${ }^{33}$ WINTGENS, Luc J. Legisprudence and the Duties of Power: A Legisprudential Assessment of Rational Legislation. In: WINTGENS, Luc J. Legisprudence: Practical Reason in Legislation. Farnham: Ashgate, 2012. P. 283-307.

${ }^{34}$ Nas palavras do próprio Luc J. Wintgens: "Facts are identifiable throughout practices, that is, in the social interaction of which they are part. Society can be roughly characterised as a varied set of practices: the practice of commerce, education, theatre playing, and so on. Facts are therefore an important part of that, though are only seen through the matrix of a practice. To know facts then is to enter into some of the practices in which they are identified or 'delt with'. Put differently, facts depend for their being known on a context of participation from where they obtain meaning. Knowledge of this meaning involves understanding that practice." (WINTGENS, Luc J. Legisprudence..., cit., p. 295).
} 
A essa altura, vai-se notando que uma das peculiaridades da legislação (em contraposição com a elaboração normativa a cargo das agências administrativas, por exemplo) é precisamente o fato de que nem sempre a atividade legislativa cumpre uma função eminentemente regulatória. Além de racional, os legisladores precisam ser democráticos, como também apontou Neil MacCormick. ${ }^{35}$ A cargo dos parlamentos, há funções políticas, constitucionais, simbólicas e democráticas, as quais não estariam sujeitas a um fact-finding rigoroso, tornando sem sentido uma eventual revisão judicial em determinadas situações, como será possível ver melhor na sequência. No Poder Legislativo, há uma vasta gama de decisões como, por exemplo, a fixação de objetivos macro de uma determinada política pública - que não precisam estar calcadas em estudos empíricos ou em uma análise de custo-benefício. Citese, para ficar em só um exemplo, a política de combate à discriminação por motivo de cor ou gênero.

\section{O controle judicial dos fatos legislativos e alguns de seus problemas}

Como se acaba de ver, de uma forma ou de outra, as decisões legislativas se apoiam em dados da realidade (ainda que não necessariamente evidências, como visto), que funcionam como "premissas fáticas" do raciocínio legislativo. Esse contexto empírico pode conduzir à intervenção legislativa ou não (caso a decisão de não legislar seja fruto de uma posição deliberada e não uma simples omissão). Essa discricionariedade dos legisladores para aprovar ou não uma lei - convém recordar - não é absoluta, na medida em que, dentro dos Estados Constitucionais, a atuação legislativa é livre somente dentro dos limites colocados pela própria Constituição.

Dessa forma, embora os legisladores tenham relativa discricionariedade para determinar fins e escolher meios, não podem contrariar a Constituição (por exemplo, fixar fins por ela proibidos), nem deixar de cumprir o dever por ela imposto no sentido de regular, proteger e promover os direitos fundamentais e políticos, bem como outros valores e princípios extraíveis

\footnotetext{
${ }^{35}$ MACCORMICK, Neil. Legislative deliberation: Notes from the European Parliament. In: WINTGENS, Luc J. (Ed.). The Theory and Practice of Legislation: Essays in Legisprudence. Burlington: Ashgate Publishing Company, 2005. P. 285-296. Nesse texto, Neil MacCormick reflete sobre sua experiência pessoal como membro do Parlamento Europeu, enfatizando como a democracia faz a diferença real na prática. A dialética dos debates promove persuasão mútua e desenvolvimento de ideias. Por isso, Neil MacCormick defende a necessidade de reconstruir o modelo de legislador racional à luz da variável democrática. Nas suas próprias palavras: "However that may be, my own experience has been that in the European Parliament, legislative processes do have a rational and discursive quality, though falling well short of perfect rationality. Decision-making is properly multi-factorial for every decision-maker, and final collective conclusions reflect many partial and partisan inputs. Nevertheless, there could be value in constructing something like Wróblewski's ideal rational legislator, in a reconstructed democratic variant." (MACCORMICK, Neil. Legislative..., cit., p. 295).
} 
do texto constitucional. Além disso, a margem de liberdade de que gozam os legisladores não é a mesma em todas as situações e varia conforme as disposições da própria Constituição. ${ }^{36}$

Ainda quanto à atuação dos legisladores dentro de um Estado Constitucional, também é possível afirmar que deles se passa a pedir a apresentação de razões, isto é, que as decisões legislativas passem a ser justificadas, com vistas a demonstrar, especialmente, que não são arbitrárias e que são proporcionais, tendo em consideração, precisamente, o contexto fático em que as decisões foram tomadas e a respectiva demarcação dos problemas jurídicos, sociais ou econômicos que com elas se pretendia resolver. Trata-se da lógica de que leis racionais são leis arrazoadas, no sentido de que tenham razões em sua defesa.

A partir do momento em que se considera essa necessidade de justificar também as decisões legislativas (atenção, aqui não se afirma que haveria um “dever" nesse sentido) ) $^{37}$, emerge a relevância da análise das decisões legislativas já não só quanto à chamada "racionalidade interna" - isto é, se a decisão tomada pode ser inferida de modo apropriado a partir de suas premissas -, mas sobretudo da perspectiva de "racionalidade externa", ou seja, se as premissas foram aceitas corretamente. ${ }^{38}$ Dito com outras palavras, seria necessário que as

\footnotetext{
36 "A título meramente ilustrativo, usando como exemplo a Constituição da República de 1988, é diferente a conformação legislativa que pode ser dada ao direito de reunião, conforme referido no art. $5^{\circ}$, inciso XI, ou ao direito de associação, conforme o respectivo inciso XX, por exemplo, e os critérios para considerar que uma propriedade rural cumpre ou não com sua função social e, consequentemente, poderá estar sujeita à desapropriação para fins de reforma agrária, à luz dos arts. 184 e seguintes da Constituição. Em outras palavras, o peso da Constituição deve ser verificado sempre a cada caso, e a posição dos legisladores ou seu poder legislativo para regular certos temas pode limitar-se a assegurar operatividade individual e social, como no caso dos direitos fundamentais que se apresentam como liberdades-autonomia. Assim, o papel da Constituição depende da estrutura concreta da norma constitucional envolvida, ou da sua densidade normativa, se se prefere. Há vários casos nos quais a liberdade legislativa é mínima. Mais exemplos nesse sentido seriam: a inviolabilidade de domicílio (art. $5^{\circ}$, inciso XI), o sigilo das comunicações (art. $5^{\circ}$, inciso XII). Do lado oposto, com muita margem estaria a disciplina da compensação devida pela exploração de petróleo e outros recursos naturais (art. 20, $\S 1^{\circ}$ ) ou a forma de distribuição dos recursos do Fundo de Participação dos Estados e do Fundo de Participação dos Municípios, cujo critério é unicamente a promoção do equilíbrio sócio-econômico entre Estados e entre Municípios (arts. 159 a 161)" (NASCIMENTO, Roberta Simões. Teoria da Legislação e Argumentação Legislativa: Brasil e Espanha em perspectiva comparada. Curitiba: Alteridade, 2019, p. 234-235).

${ }^{37}$ Para mais detalhes sobre essa discussão, confira-se: NASCIMENTO, Roberta Simões. Teoria da..., cit., p. 2135 .

${ }^{38}$ WROBLÉWSKI, Jerzy. Sentido y hecho en el Derecho. Santiago: Ediciones Olejnik, 2018, p. 39. As racionalidades interna e externa são espelhadas nas noções de justificação interna e justificação externa. A propósito da decisão judicial, Jerzy Wróblewski assim discorre sobre a justificação externa: "External justification of legal decision deals with the choices of various directives and with evaluations needed during their use. These directives and evaluations appear in the interpretation of norms, in assessing evidence of the facts of the case and in the determination of legal consequences of these facts within the provided lee-ways of decision. That justification can be hardly reduced to formalized techniques." (WROBLÉWSKI, Jerzy. Legal Decision and Its Justification. Logique et Analyse, v. 14, n. 53/54, p. 409-419, 1971, p. 418). Já quanto à justificação externa da decisão legislativa em específico, o autor não avança muito, limitando-se a registrar que a complexidade dos fenômenos sociais e as controvérsias axiológicas tornam os acordos relativos à racionalidade externa mais problemáticos. Para o argumento completo, confira-se: WRÓBLEWSKI, Jerzy. A model of rational lawmaking. ARSP: Archiv für Rechts-und Sozialphilosophie/Archives for Philosophy of Law and Social Philosophy, v. 65 , n. 2 , p. $187-201,1979$.
} 
premissas fáticas do raciocínio legislativo sejam corretas (ou, com ainda mais rigor à luz da perspectiva da legislação baseada em evidências, fundadas nos resultados mais recentes das ciências relevantes, embora neste trabalho se rejeite tal nível de exigência).

Seguindo por essa linha de raciocínio, e considerando essa cultura legislativa a ser desenvolvida dentro dos Estados Constitucionais, embora haja alguma discricionariedade legislativa quanto à decisão de legislar ou não - conforme a apreciação política à luz da realidade determinada -, não existiria espaço para um juízo quanto à realidade em si, isto é, quanto à ocorrência ou não de determinados fatos, ou eventual contestação sobre a forma com que se deram, dentro do fundamento epistêmico da decisão legislativa, por mais que essa ideia possa parecer vaga ou problemática.

Com isso, passa a ser plenamente aplicável ao plano da atuação dos legisladores uma das possibilidades mais eficazes no controle dos poderes discricionários, qual seja, o controle da veracidade dos fatos determinantes da decisão legislativa. ${ }^{39}$ Trata-se da sindicabilidade da "versão legislativa sobre a realidade" ou, como aqui se prefere, fatos determinantes da legislação, sempre e quando sejam empiricamente aferíveis e quando haja razões para duvidar da integridade do levantamento dos fatos do legislador..$^{40}$ A literatura internacional aborda a temática sob a denominação evidence-based judicial review (EBJR), ${ }^{41}$ expressão que acaba carregando uma diversidade de compreensões. ${ }^{42}$ Esse controle de constitucionalidade com base

\footnotetext{
${ }^{39}$ GARCÍA DE ENTERRÍA, Eduardo. La lucha contra las inmunidades del poder. 3. ed. Cizur Menor: Civitas, Thomson Reuters, 1983, p. 32.

${ }^{40}$ Esse ponto é importante, já que há autores que defendem uma revisão judicial ampla, ou seja, que os tribunais devem analisar o fundamento fático de todas as leis que restringem direitos individuais, independentemente de que se tratem de direitos fundamentais. A proposta de um escrutínio rigoroso ou elevado é encontrada em BORGMANN, Caitlin E. Rethinking Judicial Deference to Legislative Fact-Finding. Indiana Law Journal, v. 84, n. 1, p. 1-56, 2009. Inclusive, a autora prefere a expressão "fatos sociais" para fazer referência às questões empíricas aqui em referência.

${ }^{41}$ ALEMANNO, Alberto. The Emergence of the Evidence-Based Judicial Reflex: A Response to Bar-SimanTov's Semi-procedural Review'. The Theory and Practice of Legislation, v. 1, n. 2, p. 327-340, 2013.

${ }^{42}$ BAR-SIMAN-TOV, Ittai. The dual meaning of evidence-based judicial review of legislation. The Theory and Practice of Legislation, v. 4, n. 2, p. 107-133, 2016. Ittai Bar-Siman-Tov indica pelo menos dois sentidos do EBJR. O primeiro sentido se refere à necessidade de que a decisão judicial que examina a constitucionalidade das leis deva ser um produto de uma tomada de decisão judicial baseada em evidências, ou seja, o tribunal deve basear suas decisões em provas empíricas que possam apoiar suas conclusões. O segundo sentido do EBJR consiste na determinação de que, no exame da constitucionalidade das leis, deve-se exigir provas de que a legislação foi um produto de uma tomada de decisão baseada em evidências legislativas, isto é, propõe-se que o tribunal deva examinar se os legisladores seguiram um processo de tomada de decisão baseado em evidências. As diferenças entre um sentido e outro, como explicado no texto, apresenta importantes ramificações, tangenciando questões como os papeis dos tribunais em face dos parlamentos, as capacidades institucionais dos tribunais versus legislaturas, e a adequada divisão dos trabalhos entre legislaturas, tribunais e litigantes quanto à tomada de decisões baseadas em evidências. No presente trabalho, adota-se o que poderia ser um terceiro sentido do EBJR, aqui tomado como sinônimo da revisão judicial das premissas fáticas, independentemente da exigência de que a legislação tenha base em evidências, em decisão judicial que tampouco será baseada em evidências necessariamente.
} 
nos fatos legislativos é apontado como um terceiro tipo de controle, ${ }^{43}$ ao lado dos tradicionais voltados para os aspectos formais e substanciais (na verdade, a meio caminho entre ambos), na medida em que está voltado para verificar a qualidade do processo de tomada de decisão legislativa. ${ }^{44}$

Ocorre que existe uma tênue linha de diferença entre a margem de liberdade das escolhas legislativas e a valoração dos elementos fáticos para a tomada de decisão. ${ }^{45} \mathrm{Um}$ exemplo prático pode ajudar a compreender o que se acaba de afirmar. A Constituição estabelece a obrigação de que sejam aprovadas leis voltadas para dificultar o acesso a produtos, práticas e serviços que possam ser nocivos à saúde. Para que uma determinada substância seja incluída na lista de substâncias entorpecentes, psicotrópicas, precursoras e outras sob controle especial, a decisão legislativa pressupõe, necessariamente, a consideração sobre a efetiva nocividade da substância em concreto, ou seja, um dado fático, não sendo possível ignorar tais propriedades efetivamente atestadas no plano da realidade extrajurídica para a tomada de decisão legislativa.

\footnotetext{
${ }^{43}$ POPELIER, Patricia. Preliminary Comments on the Role of Courts as Regulatory Watchdogs. Legisprudence, v. 6, i. 3, p. 257-270, 2012.; BAR-SIMAN-TOV, Ittai. Semiprocedural Judicial Review. Legisprudence, v. 6, i. 3, p. 271-300, 2012.; POPELIER, Patricia. The Court as Regulatory Watchdog. The procedural approach in the case law of the European Court of Human Rights. In: POPELIER, Patricia; MAZMANYAN, Armen; VANDENBRUWAENE, Werner (Eds.). The Role of Constitutional Courts in Multilevel Governance. Cambridge: Intersentia, 2012. P. 249-267; VAN GESTEL, Rob; POORTER, Jurgen. Putting evidence-based law making to the test: judicial review of legislative rationality. The Theory and Practice of Legislation, v. 4, n. 2, p. 155-185, 2016; OLIVER-LALANA, A. Daniel. El control del proceso de justificación legislativa y la teoría de los princípios formales. In: PORTOCARRERO, Jorge (Ed.). Ponderación y discrecionalidad. Un debate en torno al concepto y sentido de los principios formales em la interpretación constitucional. Bogotá: Universidad Externado de Colombia, 2016. P. 311-376.

${ }^{44}$ Algumas objeções a esse controle emergente voltado medir a qualidade da deliberação legislativa foram lançadas em: NASCIMENTO, Roberta Simões. Cabe controle de constitucionalidade quanto à qualidade da deliberação legislativa? Jota, 14 out. 2020. Disponível em: https://www.jota.info/opiniao-e-analise/colunas/defensorlegis/controle-de-constitucionalidade-qualidade-deliberacao-legislativa-14102020 . Acesso em: 28 out. 2021.

${ }^{45}$ A questão discutida na Ação Direta de Inconstitucionalidade por Omissão (ADO) $n^{\circ} 22$, sobre a Lei $n^{\circ}$ 9.294/1996, que dispõe sobre as restrições ao uso e à propaganda de produtos fumígeros, bebidas alcoólicas, medicamentos, terapias e defensivos agrícolas, nos termos do art. 220, § $4^{\circ}$, da Constituição Federal, ajuda a entender o ponto. Eis o teor do referido dispositivo constitucional: "Art. 220. A manifestação do pensamento, a criação, a expressão e a informação, sob qualquer forma, processo ou veículo não sofrerão qualquer restrição, observado o disposto nesta Constituição. (...) $\S 3^{\circ}$ Compete à lei federal: (...) II - estabelecer os meios legais que garantam à pessoa e à família a possibilidade de se defenderem de programas ou programações de rádio e televisão que contrariem o disposto no art. 221, bem como da propaganda de produtos, práticas e serviços que possam ser nocivos à saúde e ao meio ambiente. $\S 4^{\circ}$ A propaganda comercial de tabaco, bebidas alcoólicas, agrotóxicos, medicamentos e terapias estará sujeita a restrições legais, nos termos do inciso II do parágrafo anterior, e conterá, sempre que necessário, advertência sobre os malefícios decorrentes de seu uso.". O questionamento pretendia ver declarada uma omissão inconstitucional quanto ao art. $1^{\circ}$, parágrafo único, da Lei $n^{\circ} 9.294 / 1996$, pelo qual consideram-se bebidas alcoólicas, para efeitos da lei, as bebidas potáveis com teor alcoólico superior a treze graus Gay Lussac. No caso, não havia uma determinação constitucional no sentido de que o legislador tinha que proibir a propaganda de "todas" as bebidas alcoólicas e, como demonstrando durante o julgamento, a decisão legislativa considerou estudos empíricos para fazer o corte de treze graus Gay Lussac. Após examinar os elementos que subsidiaram a decisão legislativa, o julgamento foi pela constitucionalidade da lei.
} 
Com isso, vê-se que qualquer raciocínio jurídico que se pretenda válido, inclusive no plano legislativo, não pode desprezar (ou contrariar) os elementos fáticos ou empíricos tomados como premissa da decisão. Justamente por isso, o próprio controle concentrado de constitucionalidade prevê a possibilidade de produção de provas para discutir a validade de normas jurídicas em abstrato, nos termos do art. $9^{\circ}, \S 1^{\circ}$, e do art. $20, \S 1^{\circ}$, da Lei $n^{\circ} 9.868 / 99,{ }^{46}$ e do art. $6^{\circ}$, § $1^{\circ}$, da 9.882/99. ${ }^{47}$ Trata-se do reconhecimento de que não é possível compreender ou avaliar a elaboração legislativa sem o seu componente factual. A realidade é uma só, de modo que os legisladores não poderiam criar uma "realidade paralela" ${ }^{48}$

No entanto, essa chamada "verificação dos fatos legislativos"49 é tema mal compreendido tanto na teoria brasileira, quanto na jurisprudência do Supremo Tribunal Federal (STF). Para começar, porque seria necessário separar o que é o exame da realidade fática como pressuposto para a racionalidade da interpretação constitucional (isto é, a utilização de argumentos empíricos) do escrutínio a respeito os fatos particulares usados como pressupostos para a decisão legislativa. Nem sempre o chamado fact-finding da jurisdição constitucional estará relacionado aos fatos legislativos e convém manter clareza quanto a essa distinção. ${ }^{50}$

\footnotetext{
${ }^{46}$ Art. $9^{\circ}(\ldots) \S 1^{\circ}$ Em caso de necessidade de esclarecimento de matéria ou circunstância de fato ou de notória insuficiência das informações existentes nos autos, poderá o relator requisitar informações adicionais, designar perito ou comissão de peritos para que emita parecer sobre a questão, ou fixar data para, em audiência pública, ouvir depoimentos de pessoas com experiência e autoridade na matéria.

Art. 20. (...) $\S 1^{\circ} \mathrm{Em}$ caso de necessidade de esclarecimento de matéria ou circunstância de fato ou de notória insuficiência das informações existentes nos autos, poderá o relator requisitar informações adicionais, designar perito ou comissão de peritos para que emita parecer sobre a questão ou fixar data para, em audiência pública, ouvir depoimentos de pessoas com experiência e autoridade na matéria.

${ }^{47}$ Art. $6^{\circ}(\ldots) \S 1^{\circ} \mathrm{Se}$ entender necessário, poderá o relator ouvir as partes nos processos que ensejaram a argüição, requisitar informações adicionais, designar perito ou comissão de peritos para que emita parecer sobre a questão, ou ainda, fixar data para declarações, em audiência pública, de pessoas com experiência e autoridade na matéria. ${ }^{48}$ No entanto, isso não impede os legisladores de estabelecerem "presunções legais", que estabelecem normativamente que um fato seja considerado como ocorrido (ou provado) com independência dos fatos concretos, em algumas situações (por exemplo, o art. 217-A do Código Penal considera crime de estupro de vulnerável a conduta de ter conjunção carnal ou praticar outro ato libidinoso com menor de 14 anos, com independência do constrangimento, mediante violência ou grave ameaça, com exigido na figura típica do estupro do art. 213) ou até que se prove o contrário (por exemplo, o princípio da presunção de inocência, a presunção de paternidade nos termos do art. 1.597 do Código Civil ou a figura da morte presumida prevista no art. $7^{\circ}$ do Código Civil, se for extremamente provável a morte de quem estava em perigo de vida ou se alguém, desaparecido em campanha ou feito prisioneiro, não for encontrado até dois anos após o término da guerra). A fixação de presunções legislativas ou ficções jurídicas é a solução para determinadas situações de incerteza que podem resultar problemáticas, funcionando como uma regra que confere uma resposta jurídica antecipada a uma categoria de fatos. Como se vê, não tem a ver com a desconsideração da realidade fática, na linha do que se comentava.

${ }^{49}$ MARTINS, Ives Gandra da Silva; MENDES, Gilmar Ferreira. Controle concentrado de constitucionalidade: Comentários à Lei n. 9.868, de 10-11-1999. 3. ed. São Paulo: Saraiva, 2009, p. 306-329; MENDES, Gilmar. Controle de Constitucionalidade: hermenêutica constitucional e revisão de fatos e prognoses legislativos pelo órgão judicial. Revista dos Tribunais, n. 766, p. 11-28, 1999.; PAIVA, Paulo. O processo constitucional e a tensão entre constitucionalismo e democracia: notas acerca do controle judicial dos fatos legislativos. In: FELLET, André; NOVELINO, Marcelo (orgs.). Constitucionalismo e democracia. Salvador: JusPudivm, 2013. P. 189-234. ${ }^{50}$ Uma terceira situação, que não será problematizada na presente oportunidade, diz respeito ao que corresponde à "hipótese de incidência" da norma, que também remete a elementos fáticos. Como sabido, a estrutura lógica de normas se compõe de dois elementos: o primeiro, o suporte fático (ou hipótese) e o segundo, o preceito
} 
Além disso, há vários tipos de fatos legislativos, cujas diferenças nem sempre são devidamente consideradas, e é possível que nem todos os fatos devam receber o mesmo tipo de escrutínio judicial. Kenneth Culp Davis, ${ }^{51}$ por exemplo, distingue os seguintes tipos (ou escalas) de fatos:

(1) de fatos estreitos e específicos a fatos amplos e gerais;

(2) de fatos centrais ou críticos para fatos de fundo ou periféricos;

(3) de suposições ou fatos prontamente aceitos a suposições ou fatos controversos;

(4) de proposições factuais que são quase inteiramente factuais a proposições um tanto factuais que são misturadas com julgamento, política ou preferência política;

(5) de fatos prováveis a fatos que não podem ser provados nem refutados e, portanto, devem ser encontrados a partir da legislação sobre os fatos, presumindo-os, impondo o ônus a uma das partes ou fazendo uma suposição informativa ou desinformada; e

(6) de fatos sobre partes imediatas ou fatos que são apenas ou principalmente por eles conhecidos a fatos sem relação com as partes imediatas.

De acordo com o argumento de Kenneth Culp Davis, quando os fatos usados na legislação são (1) estreitos e específicos, (2) centrais ou críticos, (3) controversos, (4) não misturados com julgamento ou política, (5) demonstráveis e (6) com algum grau de relação com as partes ou de seu conhecimento primordial, as partes claramente devem ter a oportunidade, antes da decisão legislativa, de contestá-los (os fatos considerados determinantes), e essa exigência poderia até ser imposta em nome do devido processo legislativo. ${ }^{52}$ Por outro lado, quando os fatos são (1) amplos e gerais, (2) de fundo ou periféricos, (3) não controversos, (4) misturados com julgamento ou política, (5) não são facilmente demonstráveis e (6) sem qualquer relação com as partes litigantes, um tribunal ou a agência podem usá-los sem nem mesmo dar conhecimento sobre qualquer possível problema de equidade no processo de redação legislativa. ${ }^{53}$

Ainda segundo Kenneth Culp Davis, quando os seis elementos se misturam, alguns em uma extremidade da escala, outros na outra, outros no meio, as duas questões sobre o quanto de suporte os fatos devem ter ou qual "proteção processual" dar às partes podem ser difíceis. O

\footnotetext{
(correspondente ao tratamento normativo). Como a hipótese fática das normas remete a fatos e dados da realidade da vida (as situações em que comportamentos que são objeto de tratamento legal), é possível que a discussão quanto à constitucionalidade de disposições se centre precisamente quanto a esse elemento normativo. A rigor, esse não seria um "fato legislativo", mas acaba sendo tratado como se fosse, como ocorreu por ocasião do julgamento da $\mathrm{ADI} \mathrm{n}^{\circ} 3.430$, que versava sobre uma lei estadual capixaba que autorizava a contratação temporária de servidores sem concurso público. O âmbito de aplicação fixado na referida lei foi a situação de "necessidade de excepcional interesse público". Após o debate dos ministros sobre situações fáticas de emergência, lei acabou sendo declarada inconstitucional.

${ }^{51}$ DAVIS, Kenneth Culp. Facts in Lawmaking. Columbia Law Review, 931, v. 80, n. 5, p. 931-942, 1980, p. 932.

${ }^{52}$ A noção de devido processo legislativo no Brasil é complexa. Para uma visão abreviada sobre o assunto, confirase: NASCIMENTO, Roberta Simões. O que é o devido processo legislativo? Jota, 17 fev. 2021. Disponível em: https://www.jota.info/opiniao-e-analise/colunas/defensor-legis/o-que-e-o-devido-processo-legislativo-17022021. Acesso em: 18 out. 2021.

${ }^{53}$ DAVIS, Kenneth Culp. Facts in..., cit., p. 933.
} 
direito não pode prever todas as combinações e permutações, e o julgamento deve ser feito em cada caso. As ideias de Kenneth Culp Davis, acredita-se, ajudam a entender melhor a complexidade do problema envolvido na revisão judicial da premissa fática da decisão legislativa.

No Brasil, a primeira vez que especialistas foram chamados para discutir um fato legislativo foi por ocasião do julgamento da Ação Direta de Inconstitucionalidade (ADI) $n^{\circ}$ 3.510, que tinha por objeto a constitucionalidade do artigo $5^{\circ}$ da Lei ${ }^{\circ} 11.105 / 2005,{ }^{54}$ norma que permite a pesquisa científica com embriões humanos nas condições indicadas. A questão factual consistia em saber "qual era o momento inicial da vida humana". Supostamente, essa demonstração indicaria se a decisão legislativa poderia permitir ou não a pesquisa genética com material humano embrionário, à luz da Constituição de 1988.

Naturalmente, as audiências públicas realizadas com especialistas não conseguiram comprovar quando é o início da vida humana. ${ }^{55}$ Além disso, havia claras disputas ideológicas que não permitiam um consenso, ainda menos científico. Ao final, a ADI foi julgada improcedente, de modo que, nesse caso, o Poder Judiciário não procedeu à revisão das provas legislativas especificamente consideradas. Na verdade, esse era um caso claro em que sequer seria cabível um escrutínio sobre os fatos legislativos, para seguir Kenneth Culp Davis.

A segunda audiência pública com especialistas conduzida pelo STF a foi realizada por ocasião do julgamento da Arguição de Descumprimento de Preceito Fundamental (ADPF) n ${ }^{\circ}$ 101, em que se discutia a constitucionalidade de uma série de normas que proibiam a importação de "pneus usados" (de segunda mão, reformados), em face das frequentes decisões judiciais de primeira instância em que tal importação vinha sendo permitida.

Após o julgamento dos expertos, o STF considerou que os fatos legislativos considerados foram corretos e justificavam a referida proibição legal de importação. Foram

\footnotetext{
${ }^{54}$ Art. $5^{\circ}$ É permitida, para fins de pesquisa e terapia, a utilização de células-tronco embrionárias obtidas de embriões humanos produzidos por fertilização in vitro e não utilizados no respectivo procedimento, atendidas as seguintes condições: I - sejam embriões inviáveis; ou II - sejam embriões congelados há 3 (três) anos ou mais, na data da publicação desta Lei, ou que, já congelados na data da publicação desta Lei, depois de completarem 3 (três) anos, contados a partir da data de congelamento. $\S 1^{\circ}$ Em qualquer caso, é necessário o consentimento dos genitores. $\S 2^{\circ}$ Instituições de pesquisa e serviços de saúde que realizem pesquisa ou terapia com células-tronco embrionárias humanas deverão submeter seus projetos à apreciação e aprovação dos respectivos comitês de ética em pesquisa. $\S 3^{\circ}$ É vedada a comercialização do material biológico a que se refere este artigo e sua prática implica o crime tipificado no art. 15 da Lei ${ }^{\circ} 9.434$, de 4 de fevereiro de 1997.

${ }^{55}$ Sobre esse ponto, convém mencionar a posição do então ministro Joaquim Barbosa, que sintetizou com clareza o cerne do problema: "Como ficou demonstrado nos autos e nos debates, nem mesmo a ciência está apta a afirmar, com precisão, o momento exato em que a vida se inicia ou, ainda, que há vida. E creio que a eventual definição desse momento biológico, por si só, não seria suficiente para solucionar adequadamente a importante questão posta nos autos, que se restringe à possibilidade de utilização de células-tronco embrionárias em pesquisas cientificas no Brasil.” (BRASIL. Supremo Tribunal Federal. ADI no 3.510. Tribunal Pleno. Rel. Min. Ayres Britto, julgado em 29 maio 2008, publicado em 28 maio 2010, p. 461).
} 
expressamente mencionados os seguintes elementos de ordem fática: a) a dificuldade de decomposição e armazenamento dos pneus; b) os problemas decorrentes de sua incineração; c) o alto índice de disseminação de doenças (como o mosquito tigre), devido ao acúmulo de pneus descartados ou "armazenados ao ar livre"; e d) o aumento do "passivo" ambiental. Assim, as graves consequências para a saúde pública e o meio ambiente foram consideradas provadas. Esses foram os fatos legislativos.

Com isso, já é possível perceber que, em se tratando de revisão de fatos legislativos, seria preciso saber: (1) se os fatos considerados, em todas as suas circunstâncias, foram adequados para embasar a legislação aprovada e, em consequência, sua constitucionalidade; e (2) se as partes interessadas deveriam ter tido oportunidade, antes da decisão legislativa, de contestar os fatos presumidos, mesmo que ainda não exista um procedimento legislativo que permita uma discussão adequada dos fatos durante a preparação do processo legislativo.

A terceira audiência pública com especialistas no STF aconteceu na ADPF nº 54, em que se discutiu a possibilidade de atuação médica com vistas à interrupção da gravidez em casos de fetos anencefálicos, deixando de lado a incidência de dispositivos penais correspondentes ao aborto. Esse caso não tratou de fato legislativo em si - na medida em que não havia uma decisão legislativa em concreto sob ataque $-{ }^{56}$ mas de esclarecimentos de ordem factual que permitissem a conclusão desejada na petição inicial no sentido de que, na ausência de cérebro, o feto não tem vida e, portanto, não seria o caso de falar no crime, pela inexistência de violação ao bem jurídico amparado pelo aborto. Mesmo assim, as explicações dos especialistas, especialmente quanto à confiabilidade dos exames que diagnosticam a anencefalia, foram decisivas para a conclusão do julgamento.

A quarta audiência pública foi realizada para esclarecer as supostas questões técnicas, científicas, administrativas, políticas, econômicas e jurídicas em relação às ações de prestação

\footnotetext{
${ }^{56}$ Para esses casos, a denominação adequada seria a de "fatos constitucionais", como prefere David L. Faigman, cujas preocupações se centram na atividade probatória levada a cabo na jurisdição constitucional nos Estados Unidos. David L. Faigman entende por fatos constitucionais todos os fatos utilizados em casos constitucionais, quer sejam utilizados para interpretar a Constituição, quer sejam relevantes para a aplicação de disposições constitucionais específicas. $\mathrm{O}$ autor entende que muitos argumentos baseados na estrutura constitucional dependem implícita ou explicitamente de hipóteses que poderiam ser objeto de ciência política ou sociologia. Para uma visão de suas ideias, confiram-se: FAIGMAN, David L. Constitutional fictions. New York: Oxford University Press, 2008; __ A Unified Theory of Constitutional Facts. Bepress Legal Series. Working Paper 1149, 2006. Disponível em: https://law.bepress.com/expresso/eps/1149. Acesso em: 27 nov. 2021; __ _ Fact-Finding in Constitutional Cases. UC Berkeley: Center for the Study of Law and Society Jurisprudence and Social Policy Program, 2005. Disponível em: https://escholarship.org/uc/item/4sj7t6n2 . Acesso em: 27 nov. 2021;

"Normative Constitutional Fact-Finding": Exploring the Empirical Component of Constitutional Interpretation. University of Pennsylvania Law Review, v. 139, n. 3, p. 541-613, 1991.
} 
de saúde do Poder Público. ${ }^{57}$ A convocação buscou esclarecer: a) a responsabilidade dos entes da federação em matéria de direito à saúde; b) a obrigação do Estado de prestar atendimento médico prescrito por médico não pertencente aos quadros do Sistema Único de Saúde (SUS) ou sem solicitação prévia à Administração Pública; c) a obrigação do Estado de pagar por benefícios de saúde não cobertos pelas políticas públicas existentes; d) obrigação do Estado de fornecer medicamentos ou tratamentos experimentais não registrados na Agência Nacional de Vigilância Sanitária (ANVISA) ou não orientados pelos Protocolos Clínicos do SUS; e) a obrigação do Estado de fornecer medicamento não licitado e não previsto nas listas do SUS; f) fraude ao SUS. Aqui, mais uma vez, o que se buscou foram subsídios empíricos para embasar a decisão judicial e interpretar e avaliar as leis em vigor. Nesse caso, o controle judicial se voltou para a consideração de fatos considerados relevantes para a interpretação constitucional, mas, como se vê, tecnicamente não se trata de um questionamento da premissa fática das leis.

A quinta vez em que o STF do Brasil recorreu a especialistas para decidir sobre a constitucionalidade das leis foi na ADPF n. 186, julgada em conjunto com RE n. 597.285, que discutiam a adoção da reserva de vagas nas universidades com base em critérios raciais (ações afirmativas ou políticas positivas). Nesse caso, também deve-se ressaltar que a utilização da audiência pública foi, não tanto para apuração de fatos legislativos propriamente ditos, mas para garantir (1) a participação dos diversos segmentos da sociedade, bem como (2) a visão mais ampla das diferentes abordagens sobre o tema das políticas de ação afirmativa para o acesso ao ensino superior.

A sexta audiência pública ocorreu no julgamento ADI n. 4.103, cujo objeto era a Lei ${ }^{\circ}$ 11.705/2008, mais conhecida como "Lei Seca", que proibia a comercialização de bebidas alcoólicas nas condições estabelecidas e reduzia a zero a tolerância ao álcool no trânsito. A audiência foi convocada para esclarecer as seguintes questões: a) efeitos das bebidas alcoólic as na direção de veículos automotores; b) reflexos no aumento do número de acidentes nas rodovias, devido à venda de bebidas alcoólicas no entorno; c) se a Lei n ${ }^{\circ} 11.705 / 2008$ trouxe benefícios específicos para a população brasileira; d) os meios científicos, invasivos ou não, para apurar, com segurança, a embriaguez incapacitante para a condução de veículos; e) o número de notificações penais e administrativas efetuadas após a referida lei; etc.

Haveria outros casos a comentar (no momento em que este texto está sendo redigido, já são 35 audiências públicas realizadas pelo STF), porém, tal aprofundamento será reservado para outra oportunidade, por limitações de tempo e espaço. A amostra é suficiente para revelar

\footnotetext{
${ }^{57}$ Suspensões de Liminares $\mathrm{n}^{\circ} 47, \mathrm{n}^{\circ}$ 64, Suspensões de Tutelas Antecipadas $\mathrm{n}^{\mathrm{o}} 36, \mathrm{n}^{\mathrm{o}} 185, \mathrm{n}^{\mathrm{o}} 211, \mathrm{n}^{\mathrm{o}} 278$, e
} Suspensões de Segurança $\mathrm{n}^{\circ} 2.361, \mathrm{n}^{\circ} 2.944, \mathrm{n}^{\circ} 3.345, \mathrm{n}^{\circ} 3.355$. 
o que importava aqui registrar: a convocação de audiências públicas para suplantar as deficiências epistêmicas do STF no Brasil vem se reduzindo mais a um espaço de abertura democrática para a participação de diferentes atores na jurisdição constitucional, com preponderância para a consideração de fatos para a decisão judicial, mas não necessariamente para o escrutínio da premissa fática da decisão legislativa propriamente dita (não estavam sendo questionados os fatos legislativos), nem com critérios claros sobre quando uma audiência pública é convocada, já que há casos em que essa providência, mesmo necessária, não ocorreu. ${ }^{58}$ Além disso, contraditoriamente, não há preocupação com o próprio caráter científico das informações recebidas pela Corte nessas audiências, nem se mencionam os problemas de capacidade de conduzir tais investigações.

A referida disfuncionalidade epistêmica verificada na prática de revisão dos fatos legislativos no Brasil, no entanto, não deve impedir a teorização sobre o assunto.

Como já é possível perceber, a porta que se abre para a possibilidade de controle judicial do fundamento epistêmico da decisão legislativa não deveria se colocar como uma instância de controle sobre a escolha formulada a partir da apreciação das opiniões e interesses divergentes em torno de uma situação fática dada. É dizer, o controle não deveria recair sobre o juízo de valoração feito no âmbito do legislativo. Além disso, essa revisão deveria contemplar as situações em que fatos ou dados tenham sido a causa da decisão legislativa (isto é, considerados determinantes), o que dependeria de que essa razão constasse expressamente das motivações. Mas nem por isso esse controle judicial se veria livre de dificuldades.

Como assinalado acima, para que uma decisão legislativa conte com justificação externa, exige-se que suas premissas sejam verdadeiras, ${ }^{59}$ o que implica a impossibilidade de os legisladores criarem uma "realidade paralela" sem correspondência no mundo dos fatos ou, por exemplo, usem dados e informações sabidamente incorretos. A partir disso, também seria possível extrair um dever de sinceridade, uma proibição de que os legisladores se valham de

\footnotetext{
${ }^{58}$ Esse foi o caso, por exemplo, da ADI $n^{\circ} 5.779$ sobre a Lei $n^{\circ} 13.454 / 2017$, que autorizava a produção, a comercialização e o consumo, sob prescrição médica, dos anorexígenos (inibidores de apetite) sibutramina, anfepramona, femproporex e mazindol. A lei foi declarada inconstitucional sem a oitiva de especialistas em audiência pública. O assunto foi comentado em NASCIMENTO, Roberta Simões. Qual peso devem ter as evidências científicas para tomar uma decisão legislativa? Jota, 27 out. 2021. Disponível em: https://www.jota.info/opiniao-e-analise/colunas/defensor-legis/inibidores-de-apetite-27102021. Acesso em: 27 out. 2021.

${ }^{59}$ Não se desconhece a divergência teórica quanto à possibilidade de atingir conhecimento verdadeiro. No entanto, para os fins do presente trabalho, basta o registro de que a verdade deve ser concebida segundo a teoria da correspondência, isto é, o sentido de verdade como ajuste entre o que se argumenta e a realidade, ou, nas palavras de Daniel González Lagier, "de palavras ao mundo”. Para a explicação desse ponto, remete-se a: GONZÁLEZ LAGIER, Daniel. Hechos y argumentos: la inferencia probatoria. In: GONZÁLEZ LAGIER, Daniel. Quaestio facti. Ensayos sobre prueba, causalidad y acción. México: Fontamara, p. 39-74, 2013, p. 67.
} 
motivos falsos para atuação legislativa ou, se se prefere, uma inexistência do direito dos legisladores à mentira. ${ }^{60}$

Isso, contudo, não significa afirmar que os legisladores busquem a "verdade" ao assentar a premissa fática na elaboração legislativa. O interesse dos parlamentares está mais voltado para alcançar a persuasão quanto à causa legislativa (que a disfunção social existente no mundo dos fatos é de uma determinada forma, e não de outra), de modo semelhante aos advogados que manejam as provas com vistas a obter uma convicção favorável dos julgadores. Aqui, está-se mais no âmbito de uma convicção psicológica, o que deveria ter consequências no âmbito do controle judicial. Em um debate parlamentar, por exemplo, por vezes, o objetivo dos legisladores favoráveis à aprovação de uma proposição é criar a convicção de que determinada proposta é melhor (e, de modo indireto, perante os eleitores ou a opinião pública, gerar a convicção de que esses mesmos legisladores ou seus partidos são melhores, ou mais preocupados com os problemas da realidade social, do que os outros).

Com isso, vê-se que a valoração das evidências pode não ter nada a ver com a verdade. ${ }^{61}$ Há claras dificuldades institucionais, teóricas e práticas para que, no plano da atuação legislativa, as evidências sejam valoradas de maneira racional, de forma justificada e controlável. Ainda não existe uma teoria ou filosofia das provas aplicável de modo específico para a decisão legislativa, ou seja, está por ser feito o trabalho de verificar o quê da literatura produzida para o raciocínio judicial pode ser transposto para o legislativo. Mas, talvez, sequer seja possível pensar em um modelo normativo para a consideração das provas no âmbito da elaboração legislativa. No máximo, a recomendação trivial no sentido de que, quanto mais informações o parlamento dispuser, melhor. Diante desse panorama, um risco é o controle judicial das premissas fáticas determinantes da legislação se converter em pretexto para substituir a decisão legislativa.

Em todo caso, ainda de forma relacionada a essa temática, não se pode deixar de menosprezar as dificuldades de comprovação empírica da falsidade dos motivos determinantes, sobretudo nas situações em que se sustente a existência de razões ocultas, não reveladas, o que incluiria os casos de corrupção dos parlamentares e compra de votos (ou mesmo da própria providência legislativa como um todo), como razão fática determinante para a aprovação das

\footnotetext{
${ }^{60} \mathrm{O}$ tema é tratado com maior aprofundamento em: NASCIMENTO, Roberta Simões. Teoria da..., cit., p. 435 e SS.

${ }^{61}$ Há casos que ilustram essa afirmação envolvendo a regulação da sacarina e do cigarro nos Estados Unidos, narrados em: FAIGMAN, David L. Legal Alchemy. The Use and Misuse of Science in the Law. New York: Freeman \& Co., 1999. Além disso, remete-se ao item anterior, em que se explica o uso estratégico das evidências.
} 
medidas legislativas. ${ }^{62}$ Embora o STF tenha reconhecido em abstrato a figura da inconstitucionalidade por vício de decoro parlamentar nas ADIs nº 4.887, 4.888 e 4.889 para essas situações, o fato é que persistem claros problemas quanto à prova desse defeito ético subjetivo dos parlamentares fora dos contextos de condenação penal. Aqui, discorda-se de que o móvel interno do parlamentar que vota a favor (ou contra) uma proposição legislativa seja relevante para validade da lei (o que importa para esses fins é só o número de votos). Mas, ainda que admitida a relevância desse elemento volitivo individual, é difícil, para não dizer impossível, produzir essa prova.

\section{Problemas e desafios emergentes da consideração de evidências na arena legislativa e da revisão judicial das evidências usadas (ou não) pelos legisladores}

Como visto até agora, por vezes existem fatos que são considerados cruciais na elaboração das leis - os chamados fatos legislativos (ainda que não necessariamente evidências) -, cuja compreensão é igualmente relevante no momento da interpretação da legislação, inclusive por ocasião da constitucionalidade das leis. No entanto, como também assinalado, a conotação do que é "evidência" e a noção de "ciência" podem ser manipuladas e usadas politicamente, isto é, como formas de legitimar (ou deslegitimar) decisões tomadas por outros motivos. Ou seja, pode-se acabar fazendo um uso não neutro dessas categorias. A politização do movimento EBP é só uma face dos desafios envolvidos na legislação baseada em evidências.

Nick Black ${ }^{63}$ esquematiza algumas razões pelas quais as evidências de pesquisa têm pouca influência nas políticas públicas de saúde: os formuladores têm objetivos diferentes da eficácia clínica (por exemplo: desenvolvimento social, financeiro, estratégico do serviço, termos e condições dos funcionários, eleitoral), evidências podem ser consideradas irrelevantes (por virem de uma especialidade diferente), pode existir falta de consenso sobre as evidências (por exemplo: são complexas, controvertidas, sujeitas a diferentes interpretações), podem surgir "evidências" concorrentes (por exemplo: experiência pessoal, informações locais, opiniões eminentes, relatórios, etc.), o ambiente social pode não ser propício à mudança da política e pode haver má qualidade dos "fornecedores de conhecimento" (isto é, das pesquisas). Esse diagnóstico sugeriria a necessidade de capacitar os próprios formuladores para que aprendam a

\footnotetext{
${ }^{62}$ NASCIMENTO, Roberta Simões. Como se prova a inconstitucionalidade por vício de decoro parlamentar? Jota, 23 dez. 2020. Disponível em: https://www.jota.info/opiniao-e-analise/colunas/defensor-legis/como-se-prova-ainconstitucionalidade-por-vicio-de-decoro-parlamentar-23122020. Acesso em: 25 out. 2021.

${ }^{63}$ BLACK, Nick. Evidence based policy: proceed with care. British Medical Journal, v. 323, n. 7307, p. 275-9, 2001.
} 
acessar fontes científicas e saibam reconhecer a qualidade das informações (e se de fato são evidências) a partir de indicadores de expertise que proporcionariam a credibilidade respectiva. ${ }^{64}$

De modo semelhante, Jeffrey J. Rachlinski ${ }^{65}$ também apresenta duas razões principais que explicariam o pouco avanço do movimento evidence-based no direito (isto é, para criar legislação baseada em evidências): a existência de objetivos contraditórios e o fato de que as pessoas não raciocinam sobre o fenômeno social de forma semelhante a como se faz na medicina e nos negócios, onde o empirismo logrou grande espaço de influência. Trata-se, com outras palavras, da tradicional assunção de que o direito não é ciência ou, se se prefere, do caráter acientífico da atividade dos juristas em geral (e dos legisladores, em especial), no sentido de que o conhecimento de nenhuma ciência, seja natural ou social, será capaz de converter a racionalidade jurídica em racionalidade científica. ${ }^{66}$ Então, ainda é preciso superar o desafio de aprender a tomar decisões com base em dados, fatos e evidências no direito.

Tudo isso revela a necessidade de que se adquira uma compreensão mais sofisticada do processo político que permeia a tomada de decisão legislativa. ${ }^{67}$ De modo especial, é necessário o entendimento de que decisões legislativas sensatas podem não refletir a racionalidade científica. Além disso, estudos empíricos sozinhos (isto é, de forma isolada) não podem ditar políticas públicas. ${ }^{68}$ A percepção desse ponto fica clara a partir do exemplo dado por Jeffrey J. Rachlinski em relação à pena de morte: independentemente do que dizem as pesquisas empíricas, mesmo que as pessoas concordassem que a pena de morte detém a criminalidade, ainda assim a pena de morte poderia ser considerada imoral ou injusta. $\mathrm{O}$ papel das evidências na decisão legislativa é mais o de qualificar o debate, como ferramenta de informação.

Então, existem justificativas múltiplas, e por vezes conflitantes, que estão por trás da maioria das escolhas legislativas. O caráter complexo do processo de tomada de decisão nos

\footnotetext{
${ }^{64}$ Conforme levantamento a cargo do Instituto de Pesquisa Econômica Aplicada (IPEA), 54\% dos servidores públicos nunca ou raramente fazem uso de relatórios ou pesquisas científicas para apoiar suas decisões, e $72 \%$ afirmaram que não existe ou que não sabem da existência de um setor em seu local de trabalho voltado para a utilização de evidências. Ainda segundo o documento, as principais fontes de informação utilizadas pelos gestores é a consulta a colegas de trabalho e a própria experiência profissional, atrás apenas de leis e normas, que figuram como a principal fonte. Confiram-se os demais números em: INSTITUTO PESQUISA ECONÔMICA APLICADA (IPEA). Em questão: Evidências para políticas públicas. N. 5, junho, 2021. Disponível em: https://www.ipea.gov.br/portal/images/stories/PDFs/em_questao/210528_policy_brief_ipea_divulgacao_05.pdf. Acesso em: 27 nov. 2021.

${ }^{65}$ RACHLINSKI, Jeffrey J. Evidence-based..., cit., p. 910.

${ }^{66}$ VON KIRCHMANN, Julius Hermann. La jurisprudencia no es ciencia. Santiago: Olejenik, 2018, p. 125. Não custa repetir a conhecida fase de Julius Hermann von Kirchmann que cristaliza essa visão: "Três palavras do legislador e bibliotecas inteiras se convertem em lixo".

${ }^{67}$ BLACK, Nick. Evidence based..., cit.

${ }^{68}$ RACHLINSKI, Jeffrey J. Evidence-based..., cit., p. 918.
} 
parlamentos faz com que não caiba em modelos simplistas de análise e avaliação. Ainda nesse contexto, convém ter presente que as circunstâncias da política funcionam por janelas de oportunidade, ${ }^{69}$ o que acaba tornando preferível aprovar uma opção second-best do que aguardar para a próxima vez em que o assunto voltar à pauta da agenda pública. Os constrangimentos da política reduzem as alternativas decisórias, mas ainda assim são essenciais para o comportamento orientado a fins..$^{70}$ Por isso, ainda parece ser necessário "ensinar" os tomadores de decisões para que aprendam a adotar soluções baseadas em dados e evidências à luz do "factível", considerando o processo político. Um curso de decisão factível é o capaz de enfrentar com êxito as restrições do mundo real. Por tudo isso, é necessário construir uma teoria lúcida e sólida sobre a apuração dos fatos (fact-finding) no âmbito legislativo e sobre como os tribunais devem abordar essa questão. Por agora, seria possível sintetizar algumas ideias centrais sobre o papel dos estudos empíricos na legislação.

Em primeiro lugar, o conhecimento empírico sozinho não pode substituir o processo democrático por intermédio do qual são conciliados os valores e os interesses em conflito. A eficácia e a efetividades de determinados cursos de ação não são os únicos critérios a nortear a ação legislativa ou estatal, de modo geral. A divergência de visões entre os atores possui valor intrínseco na política. Na verdade, é isso o que justifica a política: a tentativa de gerir os desacordos. Disso resulta que nem sempre a evidência empírica e os critérios estritamente técnicos serão determinantes, o que, por seu turno, igualmente acarreta problemas no controle judicial respectivo. Por mais que tais dados sejam importantes e devessem ser considerados no processo de tomada de decisão, os respectivos pesos vão acabar variando em cada caso. ${ }^{71} \mathrm{Em}$ resumo, como afirmam Pedro Lucas de Moura Palotti, Natália Massaco Koga e Janine Mello dos Santos, "É necessário reconhecer que soluções baseadas em evidências não se dão apartadas da política". ${ }^{72}$

Em segundo lugar, de modo relacionado com a dificuldade que se acaba de comentar, haverá situações em que as evidências existentes são inconclusivas ou objeto de divergência entre a própria comunidade científica ou ainda suscetíveis a diferentes leituras por parte dos

\footnotetext{
${ }^{69}$ KINGDON, John W. Como chega a hora de uma idéia? In: SARAVIA, Enrique; FERRAREZI, Elisabete (Org.). Políticas públicas: coletânea. Brasília: ENAP, 2006. v.1. p. 219-224; ___ Juntando as coisas. In: SARAVIA, Enrique e FERRAREZI, Elisabete (org.). Políticas públicas: coletânea. Brasília: ENAP, 2006. v.1. pp. 225-245; . Agendas, alternatives and public policies. New York: Harper Collins College Publishers, 1995.

${ }^{70}$ MAJONE, Giandomenico. La factibilidad de las políticas sociales. In: AGUILAR VILLANUEVA, Luis F. (Ed.). La hechura de las políticas públicas. México: Porrúa, 2007. P, 393-432, p. 395.

${ }^{71}$ NASCIMENTO, Roberta Simões. Qual peso..., cit.

${ }^{72}$ PALOTTI, Pedro Lucas de Moura; KOGA, Natália Massaco; SANTOS, Janine Mello dos. Ainda sobre o uso de evidências em políticas públicas. Folha, 14 set. 2021. Disponível em: https://folha.com/q9v3xmh0. Acesso em: 27 nov. 2021
} 
grupos interessados. Por isso, é preciso tomar cuidado com o uso da palavra evidência como sinônimo de algo inequívoco, na medida em que as evidências também podem estar sujeitas a diversas interpretações ou sugerir diferentes cursos de ação. Parte dos conflitos pode ser solucionada com a exposição clara da ordem de prioridades entre os objetivos a serem perseguidos com a política pública (por exemplo, durante uma pandemia, em primeiro lugar salvar vidas, em segundo lugar combater a fome, e em terceiro lugar proteger os empregos).

Nessas situações, convém respeitar os espaços de escolha democrática a cargo do Congresso Nacional, até mesmo como forma de viabilizar o experimentalismo e a oportunidade para o surgimento de evidências com base nas políticas públicas adotadas anteriormente. ${ }^{73} \mathrm{E}$ essas evidências - como resultado da avaliação das leis (ou políticas públicas) já em curso tendem a ter mais peso nas futuras decisões legislativas. Inclusive, mais promissor do que o caminho das políticas públicas baseadas em evidências parecer ser o das evidências com base nas políticas públicas.

Em terceiro lugar, cumpre registrar que existem fatos que não podem ser provados ou refutados. Para esses casos, de acordo com Kenneth Culp Davis, a providência é precisamente legislar:

\begin{abstract}
Quando os fatos necessários não são passíveis de prova, as legislaturas, tribunais ou agências podem legislar sobre eles. Por exemplo, até que a ciência forneça a resposta, um estatuto, regulamento ou decisão que trate o que é cancerígeno em ratos como cancerígeno em humanos é racional e pode ser desejável. A forma usual de legislar os fatos é a presunção ou a atribuição do ônus da prova - uma forma que é inteiramente legítima para fatos não comprováveis. Mas especialmente prejudicial à causa da garantia de uma fundamentação apropriada para a legislação é a manipulação do Supremo Tribunal das presunções ou ônus quando os fatos podem ser provados ou refutados. ${ }^{74}$
\end{abstract}

Por isso, em quarto lugar, no que diz respeito ao ônus da prova, parece justificado que aqueles que contestam a decisão legislativa são os que devem convencer o tribunal de que os fatos legislativos considerados na tomada de decisão não podem ser razoavelmente concebidos como verdadeiros. Este parece ser um critério processual importante para a corte, sem prejuízo da realização de audiências públicas, de preferência com paridade numérica de expertos a favor

\footnotetext{
${ }^{73}$ NASCIMENTO, Roberta Simões. Qual peso..., cit.

${ }^{74}$ No original: "When needed facts are unprovable, legislatures, courts, or agencies may legislate them. For instance, until science provides the answer, a statute, regulation, or decision that treats what is carcinogenic in mice as carcinogenic in humans is rational and may be desirable. The usual form of legislating facts is through a presumption or an allocation of burden of proof $-\mathrm{a}$ form that is entirely legitimate for unprovable facts. But especially damaging to the cause of assuring a proper actual foundation for lawmaking is the Supreme Court's manipulation of presumptions or burdens when facts may be proved or disproved" (DAVIS, Kenneth Culp. Facts in..., cit., p. 938).
} 
e contra os fatos legislativos controversos, de forma a garantir a imparcialidade para com os lados da controvérsia.

Em quinto lugar, considerando o caráter dinâmico do mundo dos fatos, não se pode deixar de mencionar a possibilidade de que os legisladores não tenham sido capazes de antecipar determinadas consequências ou tenham falhado na determinação dos estados de coisas que ocorreriam no mundo dos fatos após a aprovação da lei. Além disso, no caso de os legisladores terem tomado uma decisão em situações de incerteza científica, os avanços da ciência podem acabar confirmando ou não o acerto da decisão política adotada "de forma cega", isto é, sem qualquer referência à ciência. Em algumas situações, de fato não subsistiriam os fatos legislativos considerados, mas a questão é saber se, só por essa razão, a lei se torna inconstitucional. Possivelmente, o controle de constitucionalidade não é adequado para organizar os debates sobre decisões legislativas adotadas em contextos de incerteza científica.

O mesmo pode ser dito em relação à responsabilidade civil dos legisladores pelos danos causados, uma vez superada a incerteza científica. Dependendo da situação, os eventuais "erros legislativos"75 poderiam ficar a cargo da própria correção legislativa como providência natural inerente ao dever de monitoramento ou devido processo pós-legislativo. ${ }^{76}$ Assim, sobretudo nas situações em que há dificuldades com os prognósticos, haveria a obrigação dos legisladores de, a partir da avaliação restrospectiva ou ex post, verificar o alcance ou não das expectativas legislativas ou se há proteção deficiente do direito envolvido. Aqui, novamente, apresenta-se o problema do peso das novas evidências para a decisão legislativa.

\section{Conclusões}

O trabalho abordou a valoração dos fatos na decisão legislativa e indicou alguns problemas na revisão judicial respectiva. Parece restar ultrapassada a compreensão disseminada de que os legisladores, pelo simples fato de serem representantes diretos do povo, poderiam elaborar leis ignorando fatos, razões ou qualquer outra necessidade de motivar suas decisões a partir de bases empíricas que a justifiquem. A devida consideração das variáveis fáticas na atividade legislativa implicaria basear as decisões em fontes e dados adequados, que tenham correspondência empírica, mesmo que não se exijam evidências em sentido estrito para todos

\footnotetext{
${ }^{75}$ NASCIMENTO, Roberta Simões. A responsabilidade por 'erro legislativo'. Jota, 11 nov. 2020. Disponível em: https://www.jota.info/opiniao-e-analise/colunas/defensor-legis/a-responsabilidade-por-erro-legislativo11112020. Acesso em: 29 out. 2021.

${ }^{76}$ Para uma visão geral do assunto: OLIVER-LALANA, A. Daniel. Due Post-legislative Process? On the Lawmakers' Constitutional Duties of Monitoring and Revision. In: MEßERSCHMIDT, Klaus; OLIVERLALANA, A. Daniel. Rational Lawmaking under Review. Legisprudence According to the German Federal Constitutional Court. Dordrecht: Springer, 2016. P. 257-294.
} 
os casos. Mas, como observado, o conhecimento científico não é um valor absoluto (ao redor do qual devam girar as considerações sobre direitos, bens e valores a serem protegidos juridicamente por uma decisão legislativa) e existem dificuldades conceituais envolvendo as noções de fatos legislativos e evidências, cujo peso nem sempre será determinante para o curso de ação escolhido, devendo-se reconhecer o espaço dos parlamentos sobretudo nas situações de grande desacordo moral (com juízos de valores em conflito), e diante da divergência da própria comunidade científica quanto às evidências ou quando essas são inconclusivas.

A despeito disso, viu-se a importância da premissa fática do raciocínio legislativo e como a valoração dos fatos na seara legislativa pode ser uma ferramenta útil para aperfeiçoar as decisões e intervenções legislativas, sendo necessário dedicar mais atenção ao tema com vistas à construção de uma teoria adequada do fact-finding legislativo. De modo especial, fica pendente a tarefa de conciliar os avanços teóricos com vistas a racionalizar a valoração da prova no âmbito legislativo com as perspectivas políticas e democráticas, que prezam pelo caráter plural e inclusivo do processo legislativo. Como indicado, a utilização de evidências se dá em um contexto e um processo que são essencialmente políticos dentro dos parlamentos.

No que diz respeito ao controle judicial dos fatos legislativos determinantes, mostrouse a possibilidade desse escrutínio quanto à veracidade da versão legislativa da realidade, a partir do exame dos elementos empíricos que fundamentaram a adoção da medida legislativa. Nada obstante, apontou-se a disfuncionalidade da prática brasileira do chamado evidence-based judicial review (até agora com mais foco na promoção de participação do que propriamente para a apreensão da premissa fática legislativa, que sequer foi objeto de questionamento em algumas situações). Explicou-se que a literatura internacional aborda esse controle (aqui ainda incipiente) como uma realidade, inserindo-o como um tertium genus do controle de constitucionalidade, ao lado dos controles formal e material.

Os alertas que poderiam ser feitos a essa revisão judicial vão em duas linhas: a primeira, o perigo de "administrativização" dos parlamentos - como visto, uma das peculiaridades da teoria da legislação diz respeito, precisamente, à incorporação de interesses e valores políticos, de modo que exigir uma legislação baseada em evidências em todos os casos poderia converter os parlamentos em agências; e a segunda, consistente no risco de, a partir desse tipo de processo de legislative fact-finding, converter a jurisdição constitucional em um processo administrativo ou legislativo duplicado, como pretexto com vistas à sobreposição da decisão legislativa.

Por isso, quando determinantes para a decisão, os legisladores deveriam fazer referência expressa aos fatos considerados como base para a intervenção legislativa e os tribunais, por mais que possam realizar o controle dos fatos determinantes, devem se abster da revisão sem 
informações sólidas sobre os fatos considerados cruciais (ou seja, os tribunais precisariam adotar o mesmo rigor que exigem para os parlamentos tomarem uma decisão). Além disso, os tribunais constitucionais precisam adotar alguns procedimentos, na linha dos sugeridos neste trabalho, a fim de reduzir as dificuldades e problemas envolvidos nesta atividade de revisão judicial dos fatos determinantes da legislação.

\section{Referências.}

ALEMANNO, Alberto. The Emergence of the Evidence-Based Judicial Reflex: A Response to Bar-Siman-Tov's Semi-procedural Review'. The Theory and Practice of Legislation, v. 1, n. 2, p. 327-340, 2013.

ALMEIDA, Acir. Heterogeneidade de preferências e o uso de evidências na Câmara dos Ceputados. In: BOLETIM de Análise Político-Institucional. Usos de evidências em políticas públicas federais, n. 24. Brasília: Instituto de Pesquisa Econômica Aplicada (IPEA), 2020. P. 115-124.

AMARA, Nabil; OUIMET, Mathieu; LANDRY, Réjean. New evidence on instrumental, conceptual, and symbolic utilization of university research in government agencies. Science Communication, v. 26, n. 1, p. 75-106, 2004.

BARDACH, Eugene. A Practical Guide for Policy Analysis. The Eightfold Path to More Effective Problem Solving. 4. ed. Thousand Oaks: CQ Press, 2012.

BAR-SIMAN-TOV, Ittai. The dual meaning of evidence-based judicial review of legislation. The Theory and Practice of Legislation, v. 4, n. 2, p. 107-133, 2016.

Semiprocedural Judicial Review. Legisprudence, v. 6, i. 3, p. 271-300, 2012.

BERGER, Peter L; LUCKMANN, Thomas. A construção social da realidade: tratado de sociologia do conhecimento. 36 ed. Petrópolis: Vozes, 2014.

BLACK, Nick. Evidence based policy: proceed with care. British Medical Journal, v. 323, n. 7307, p. 275-9, 2001.

BORGMANN, Caitlin E. Rethinking Judicial Deference to Legislative Fact-Finding. Indiana Law Journal, v. 84, n. 1, p. 1-56, 2009.

BRASIL. Supremo Tribunal Federal. ADI n 3.510 . Tribunal Pleno. Rel. Min. Ayres Britto, julgado em 29 maio 2008, publicado em 28 maio 2010.

COSTA, Marcelo Marchesini da et al. O que são evidências para políticas públicas? Folha de São Paulo, 21/08/2021. Disponível em: https://folha.com/ia8f73eq. Acesso em: 19 set. 2021.

DAVIS, Kenneth Culp. An approach to problems of evidence in the administrative process. Harvard Law Review, v. 55, n. 3, 1942, pp. 364-425. 
Facts in Lawmaking. Columbia Law Review, 931, v. 80, n. 5, p. 931-942, 1980.

DELLEY, Jean-Daniel. Pensar a lei. Introdução ao pensamento metódico. Cadernos da Escola do Legislativo, v. 7, n. 12, p. 101-143, jan./jun. 2004.

EISENBERG, Theodore. Why Do Empirical Legal Scholarship? San Diego Law Review, v. 41, n. 4, p. 1741-1746, 2004.

FAIGMAN, David L. Constitutional fictions. New York: Oxford University Press, 2008.

A Unified Theory of Constitutional Facts. Bepress Legal Series. Working Paper 1149, 2006. Disponível em: https://law.bepress.com/expresso/eps/1149. Acesso em: 27 nov. 2021.

Fact-Finding in Constitutional Cases. UC Berkeley: Center for the Study of Law and Society Jurisprudence and Social Policy Program, 2005. Disponível em: https://escholarship.org/uc/item/4sj7t6n2. Acesso em: 27 nov. 2021. Co., 1999.

Legal Alchemy. The Use and Misuse of Science in the Law. New York: Freeman \& . "Normative Constitutional Fact-Finding": Exploring the Empirical Component of Constitutional Interpretation. University of Pennsylvania Law Review, v. 139, n. 3, p. 541$613,1991$.

FERREIRA, Helder. Análise de qualidade de evidências científicas utilizadas em política pública: aplicação a documentos relativos à tramitação do PL $\mathrm{n}^{\circ} 3.722 / 2012$, que flexibiliza o controle de armas de fogo. In: BOLETIM de Análise Político-Institucional. Usos de evidências em políticas públicas federais, n. 24. Brasília: Instituto de Pesquisa Econômica Aplicada (IPEA), 2020. P. 125-134.

FRENCH, Richard D. Evidence-Based Policy: Four Schools of Thought. Canadian Public Administration, n. 61, i. 3, p. 1-29, 2018.

GARCÍA DE ENTERRÍA, Eduardo. La lucha contra las inmunidades del poder. 3. ed. Cizur Menor: Civitas, Thomson Reuters, 1983.

GONZÁLEZ LAGIER, Daniel. Hechos y argumentos: la inferencia probatoria. In:

GONZÁLEZ LAGIER, Daniel. Quaestio facti. Ensayos sobre prueba, causalidad y acción. México: Fontamara, 2013. P. 39-74.

HAM, Chris; HUNTER, David; ROBINSON, Ray. Evidence based policy making. Research must inform health policy as well as medical care. BMJ, v. 310, p. 71-72, 14 jan. 1995.

INSTITUTO PESQUISA ECONÔMICA APLICADA (IPEA). Em questão: Evidências para políticas públicas. n. 5, junho, 2021. Disponível em:

https://www.ipea.gov.br/portal/images/stories/PDFs/em_questao/210528_policy_brief_ipea_d ivulgacao_05.pdf. Acesso em: 27 nov. 2021. 
KINGDON, John W. Como chega a hora de uma idéia? In: SARAVIA, Enrique; FERRAREZI, Elisabete (Org.). Políticas públicas: coletânea. Brasília: ENAP, 2006. v.1. P. 219-224.

. Agendas, alternatives and public policies. New York: Harper Collins College Publishers, 1995

. Juntando as coisas. In: SARAVIA, Enrique e FERRAREZI, Elisabete (org.). Políticas públicas: coletânea. Brasília: ENAP, 2006. v.1. P. 225-245.

KOSTI, Nir; LEVI-FAUR, David; MOR, Guy. Legislation and regulation: three analytical distinctions. The Theory and Practice of Legislation, v. 7, n. 3, p. 169-178, 2019.

MACCORMICK, Neil. Legislative deliberation: Notes from the European Parliament. In: WINTGENS, Luc J. (Ed.). The Theory and Practice of Legislation: Essays in Legisprudence. Burlington: Ashgate Publishing Company, 2005. P. 285-296.

MACINTYRE, Sally; PETTICREW, Mark. Good intentions and received wisdom are not enough. Journal of Epidemiology \& Community Health, v. 54, i. 11, p. 802-803, 2000.

MAJONE, Giandomenico. Evidence, Argument, and Persuasion in the Policy Process. New Haven: Yale University Press, 1989.

La factibilidad de las políticas sociales. In: AGUILAR VILLANUEVA, Luis F. (Ed.). La hechura de las políticas públicas. México: Porrúa, 2007. P, 393-432.

MARTINS, Ives Gandra da Silva; MENDES, Gilmar Ferreira. Controle concentrado de constitucionalidade: Comentários à Lei n. 9.868, de 10-11-1999. 3. ed. São Paulo: Saraiva, 2009. P. 306-329.

MENDES, Gilmar. Controle de Constitucionalidade: hermenêutica constitucional e revisão de fatos e prognoses legislativos pelo órgão judicial. Revista dos Tribunais, n. 766, p. 11-28, 1999.

NASCIMENTO, Roberta Simões. A responsabilidade por 'erro legislativo'. Jota, 11 nov. 2020. Disponível em: https://www.jota.info/opiniao-e-analise/colunas/defensor-legis/aresponsabilidade-por-erro-legislativo-11112020. Acesso em: 29 out. 2021.

. Cabe controle de constitucionalidade quanto à qualidade da deliberação legislativa? Jota, 14 out. 2020. Disponível em: https://www.jota.info/opiniao-e-analise/colunas/defensorlegis/controle-de-constitucionalidade-qualidade-deliberacao-legislativa-14102020. Acesso em: 28 out. 2021.

Como se prova a inconstitucionalidade por vício de decoro parlamentar? Jota, 23/12/2020. Disponível em: https://www.jota.info/opiniao-e-analise/colunas/defensorlegis/como-se-prova-a-inconstitucionalidade-por-vicio-de-decoro-parlamentar-23122020. Acesso em: 25 out. 2021. 
Qual peso devem ter as evidências científicas para tomar uma decisão legislativa?

Jota, 27 out. 2021. Disponível em: https://www.jota.info/opiniao-e-analise/colunas/defensorlegis/inibidores-de-apetite-27102021. Acesso em: 27 out. 2021.

O que é o devido processo legislativo? Jota, 17 fev. 2021. Disponível em:

https://www.jota.info/opiniao-e-analise/colunas/defensor-legis/o-que-e-o-devido-processolegislativo-17022021. Acesso em: 18 out. 2021.

Teoria da Legislação e Argumentação Legislativa: Brasil e Espanha em perspectiva comparada. Curitiba: Alteridade, 2019.

OLIVER-LALANA, A. Daniel. Due Post-legislative Process? On the Lawmakers' Constitutional Duties of Monitoring and Revision. In: MEßERSCHMIDT, Klaus; OLIVERLALANA, A. Daniel. Rational Lawmaking under Review. Legisprudence According to the German Federal Constitutional Court. Dordrecht: Springer, 2016. P. 257-294.

El control del proceso de justificación legislativa y la teoría de los princípios formales. In: PORTOCARRERO, Jorge (Ed.). Ponderación y discrecionalidad. Un debate en torno al concepto y sentido de los principios formales em la interpretación constitucional. Bogotá: Universidad Externado de Colombia, 2016. P. 311-376.

PAIVA, Paulo. O processo constitucional e a tensão entre constitucionalismo e democracia: notas acerca do controle judicial dos fatos legislativos. In: FELLET, André; NOVELINO, Marcelo (orgs.). Constitucionalismo e democracia. Salvador: JusPudivm, 2013. P. 189-234.

PALOTTI, Pedro Lucas de Moura; KOGA, Natália Massaco; SANTOS, Janine Mello dos. Ainda sobre o uso de evidências em políticas públicas. Folha, 14 set. 2021. Disponível em: https://folha.com/q9v3xmh0. Acesso em: 27 nov. 2021.

PINHEIRO, Maurício Mota Saboya. Políticas públicas baseadas em evidências: uma avaliação crítica. In: BOLETIM de Análise Político-Institucional. Usos de evidências em políticas públicas federais, n. 24. Brasília: Instituto de Pesquisa Econômica Aplicada (IPEA), 2020, p. 17-27.

POPELIER, Patricia. Preliminary Comments on the Role of Courts as Regulatory Watchdogs. Legisprudence, v. 6, i. 3, p. 257-270, 2012.

POPELIER, Patricia. The Court as Regulatory Watchdog. The procedural approach in the case law of the European Court of Human Rights. In: POPELIER, Patricia; MAZMANYAN, Armen; VANDENBRUWAENE, Werner (Eds.). The Role of Constitutional Courts in Multilevel Governance. Cambridge: Intersentia, 2012. P. 249-267

POPELIER, Patricia; VERLINDEN, Victoria. The Context of the Rise of Ex Ante Evaluation. In: VERSCHUUREN, Jonathan (Ed.). The Impact of Legislation: A Critical Analysis of Ex Ante Evaluation. Boston: Martinus Nijhoff Publishers, 2009. P. 13-37.

RACHLINSKI, Jeffrey J. Evidence-based law. Cornell Law Review, v. 96, i. 4, p. 901-924, 2011, p. 910.

RACHLINSKI, Jeffrey J.; FARINA, Cynthia R. Cognitive Psychology and Optimal Government Design. Cornell Law Review, v. 87, n. 2, p. 549-615, 2002. 
SIMON, Herbert A. El comportamiento administrativo. Estudio de los procesos decisorios en la organización administrativa. Madrid: Aguilar, 1970.

SUNSTEIN, Cass R.; VERMEULE, Adrian. Interpretation and Institutions. Michigan Law Review, v. 101, n. 4, p. 885-951, 2003.

WALDRON, Jeremy. Political political theory: essays on institutions. Cambridge: Harvard University Press, 2016.

Principles of legislation. In: BAUMAN, Richard W.; KAHANA, Tsvi (Eds.). The Least Examined Brach: the Role of Legislatures in the Constitutional State. Cambridge: Cambridge University Press, 2006. P. 15-32.

Derecho y desacuerdos. Madrid: Marcial Pons, 2005.

A dignidade da legislação. São Paulo: Martins Fontes, 2003.

VAN GESTEL, Rob; POORTER, Jurgen. Putting evidence-based law making to the test: judicial review of legislative rationality. The Theory and Practice of Legislation, v. 4, n. 2, p. 155-185, 2016.

VON KIRCHMANN, Julius Hermann. La jurisprudencia no es ciencia. Santiago: Olejenik, 2018.

WINTGENS, Luc J. Legisprudence and the Duties of Power: A Legisprudential Assessment of Rational Legislation. In: WINTGENS, Luc J. Legisprudence: Practical Reason in Legislation. Farnham: Ashgate, 2012. P. 283-307.

WOOLHANDLER, Ann. Rethinking the Judicial Reception of Legislative Facts. Vanderbilt Law Review, v. 41, n. 1, p. 111-126, 1988.

WROBLÉWSKI, Jerzy. Sentido y hecho en el Derecho. Santiago: Ediciones Olejnik, 2018. 1971.

Legal Decision and Its Justification. Logique et Analyse, v. 14, n. 53/54, p. 409-419,

Recebido em: 25/11/2021

$1^{\circ}$ Parecer: 06/12/2021

$2^{\circ}$ Parecer: 30/11/2021 